Sônia Christina Leme Stach

\title{
Fatores preditivos de morbimortalidade materna nos partos de gestações gemelares
}

\author{
Dissertação apresentada à Faculdade de \\ Medicina da Universidade de São Paulo para \\ obtenção do título de Mestre em Ciências \\ Programa de Obstetrícia e Ginecologia \\ Orientador: Prof. Dr. Adolfo Wenjaw Liao
}

São Paulo

2012 
Dados Internacionais de Catalogação na Publicação (CIP)

Preparada pela Biblioteca da

Faculdade de Medicina da Universidade de São Paulo

Creprodução autorizada pelo autor

Stach, Sônia Christina Leme

Fatores preditivos de morbimortalidade materna nos partos de gestações gemelares

/ Sônia Christina Leme Stach. -- São Paulo, 2012.

Dissertação(mestrado)--Faculdade de Medicina da Universidade de São Paulo. Programa de Obstetrícia e Ginecologia.

Orientador: Adolfo Wenjaw Liao.

Descritores: 1.Gravidez de gêmeos 2.Parto 3.Parto normal 4.Cesárea 5.Complicações do parto

USP/FM/DBD-403/12 
À minha mãe, Maria Isabel (in memorian), que com sua força e bondade conquistou a todos. Você foi e permanece sendo a rocha, na qual nos apoiamos. Com seu amor e alegria, sempre nos fez acreditar no arcoíris após a chuva. O meu amor por você é eterno.

À minha avó, Ninfa (in memorian), minha segunda mãe, que levo sempre comigo, você é uma parte de mim. Você me ensinou o amor pelo conhecimento e cultura. Tua alma agora viaja livre, mas a vaga música nos une.

Ao meu pai, Waldemar, símbolo de maior amor, em seus braços meus sonhos e medos foram acalentados. Você me ensinou, com sabedoria, a caminhar. Com sua sinceridade, tornou-se meu melhor conselheiro. Com sua docilidade, me ensinou a amar.

Ao meu irmão, Nelson, que me ensinou o significado do verbo compartilhar. Tiver a sorte de ter nascido com meu melhor amigo. Sua cumplicidade sempre me fortaleceu. O destino nos deu uma herança de amor para além das estrelas a partilhar. 
Ao Professor Dr Marcelo Zugaib, digníssimo Professor Titular de Obstetrícia do Departamento de Obstetrícia e Ginecologia da Faculdade de Medicina da Universidade de São Paulo, por permitir esta oportunidade única de aprendizado neste tão conceituado Departamento de Obstetrícia da Faculdade de Medicina da Universidade de São Paulo

Ao Professor Dr Adolfo Wenjaw Liao, ao qual aprendi, nestes anos de convivência, cada vez mais, a admirar, não apenas pelo profuso conhecimento médico, como também pelas excepcionais qualidades como ser humano. Obrigada por me conduzir de maneira delicada durante a tempestade. Sinceramente obrigada.

À Professora Dra Maria de Lourdes Brizot, que com admirável competência nos guia a sermos, não somente melhores profissionais, como também melhores indivíduos. Obrigada por sua compreensão nos momentos difíceis. 
À Professora Dra Mary Angela Parpinelli, presente na banca de qualificação, pelas valiosas considerações para o aprimoramento deste trabalho.

À Professora Dra Vera Lúcia Krebs, pela valiosa ajuda no desenvolvimento deste trabalho e também por suas considerações na qualificação.

Á Professora Dra Roseli Mieko Yamamoto Nomura, obrigada pelas importantes observações na qualificação que ajudaram na finalização deste trabalho.

Ao Professor Dr Vitor Bunduki, o primeiro a me incentivar a realizar esta pós-graduação. Obrigada pela ajuda.

À Dra Maria Rita de Figueiredo Lemos Bortolloto, por sua incansável ajuda e orientação nestes muitos anos de convivência.

Aos colegas do Setor de Gestações Gemelares da Clínica Obstétrica do Hospital das Clínicas da Universidade de São Paulo, especialmente à Dra. Fernanda Cristina Ferreira, à Dra. Carolina Hofmeister, Dr Fábio Roberto Cabar e ao Dr Wagner Hernandez.

À Dra Joelma Queiroz Andrade, obrigada pela colaboração e ajuda.

À Dra Eliane Azeka Hase, obrigada, acima de tudo, pela amizade.

Ao Dr Marco Aurélio Knippel Galletta, obrigada pelas considerações acerca deste trabalho.

Às grandes amigas Dra Fernanda Spadotto, Dra Erika Ussami, Dra Nanci Utida, Sabine Dittmers, Diva Glasser Leme e Nympha Savalle. A amizade é uma das mais belas formas de amor.

Ao Sr Amadeu Santos, cuja ajuda foi muito importante na obtenção dos dados deste trabalho

Às Sras Soraia Cristina Ferreira da Silva, Adriana Regina Festa e Márcia Aparecida Batista, secretárias da Clínica Obstétrica, por toda ajuda.

À todos os mestres da Clínica Obstétrica do Hospital das Clínicas da Universidade de São Paulo, que com sabedoria me ensinaram a arte da obstetrícia, desde a minha graduação.

À todas as pacientes do Setor de Gestações Gemelares da Clínica Obstétrica do Hospital das Clínicas da Universidade de São Paulo,por que ser mãe é assumir o papel divino da criação. 
Adágio em sol menor para violino, cordas e órgão, Tomaso Albinoni 
Esta dissertação ou tese está de acordo com as seguintes normas, em vigor no momento desta publicação:

Referências: adaptado de International Committee of Medical Journals Editors (Vancouver).

Universidade de São Paulo. Faculdade de Medicina. Divisão de Biblioteca e Documentação. Guia de apresentação de dissertações, teses e monografias. Elaborado por Anneliese Carneiro da Cunha, Maria Julia de A. L. Freddi, Maria F. Crestana, Marinalva de Souza Aragão, Suely Campos Cardoso, Valéria Vilhena. 3a ed. São Paulo: Divisão de Biblioteca e Documentação; 2011.

Abreviaturas dos títulos dos periódicos de acordo com List of Journals Indexed in Index Medicus. 
LISTA DE ABREVIATURAS, SIGLAS E SÍMBOLOS

LISTA DE TABELAS

LISTA DE FIGURAS

RESUMO

SUMMARY

1 - INTRODUÇÃO

2 - OBJETIVOS

3 - REVISÃO DE LITERATURA 6

4 - MÉTODOS 28

5 - CARACTERIZAÇÃO DA AMOSTRA 34

6 - RESULTADOS

7 - DISCUSSÃO

8 - CONCLUSÃO 62

9 - ANEXOS 63

10 - REFERÊNCIA BIBLIOGRÁFICA 69 


\begin{tabular}{|c|c|}
\hline ACOG & "American College of Obstetrician and Gynecologists" \\
\hline AVC & Acidente vascular cerebral \\
\hline $\mathrm{BCP}$ & Broncopneumonia \\
\hline CAPPESQ & Comissão de Ética para Análise de Projetos de Pesquisa \\
\hline CesE & Cesárea eletiva \\
\hline CesU & Cesárea urgente \\
\hline DHEG & Doença hipertensiva específica da gravidez \\
\hline DPP & Descolamento prematuro de placenta \\
\hline et al & e outros \\
\hline G1 & Primeiro gemelar \\
\hline G2 & Segundo gemelar \\
\hline HTA & Histerectomia total abdominal \\
\hline HCFMUSP & $\begin{array}{l}\text { Hospital das Clínicas da Faculdade de Medicina da } \\
\text { Universidade de São Paulo }\end{array}$ \\
\hline HIV+/AIDS & $\begin{array}{l}\text { Paciente portadora do vírus da imunodeficiência humana } \\
\text { adquirida ou de Sindrome de imunodeficiência adquirida }\end{array}$ \\
\hline IG & Idade gestacional \\
\hline IC & Intervalo de confiança \\
\hline LA & Líquido amniótico \\
\hline$P$ & Nível de significância \\
\hline PP & Placenta prévia \\
\hline RCUI & Restrição de crescimento intra-útero \\
\hline $\mathrm{RR}$ & Risco relativo \\
\hline RPMO & Rotura prematura de membranas \\
\hline $\mathrm{ROC}$ & "Receiver operating characteristic" \\
\hline sem & semanas \\
\hline SOGC & "Society of Obstetricians and Gynaecologist of Canada" \\
\hline
\end{tabular}


Lista de abreviaturas, siglas e símbolos

$\begin{array}{ll}\text { TEV } & \text { Tromboembolismo venoso } \\ \text { UTI } & \text { Unidade de Terapia Intensiva } \\ \text { VAG } & \text { Parto vaginal } \\ < & \text { menor } \\ \leq & \text { menor ou igual } \\ > & \text { maior } \\ > & \text { maior ou igual }\end{array}$


Tabela 1 Características maternas e dados gestacionais em

página

817 pacientes com gestações gemelares de acordo com a via de parto, (HCFMUSP-1993-2008).

Tabela 2 Motivo da internação de 817 pacientes com gestação gemelar na Clínica Obstétrica do HCFMUSP entre 1993 a 2008.

Tabela 3 Motivo da resolução da gestação em 817 pacientes com gestação gemelar na Clínica Obstétrica do HCFMUSP entre 1993 a 2008.

Tabela 4 Indicação da cesariana realizada no HCFMUSP em 686 pacientes com gestação gemelar no período de 1993 a 2008.

Tabela 5 Frequência de doença materna grave nas pacientes com gestação de alto risco no momento da indicação da via de parto em 143 pacientes submetidas a parto no HCFMUSP entre 1993 e 2008.

Tabela 6 Complicações puerperais em partos de gestações gemelares ocorridas no HCFMUSP de acordo com a via de parto realizada no período de 1993 a 2008.

Tabela 7 Níveis de significância para as variáveis independentes na análise da predição de qualquer complicação materna nos partos de gestações gemelares ocorridas no HCFMUSP entre 1993 a 2008.

Tabela 8 Evolução temporal das complicações puerperais em Gestações gemelares, no HCFMUSP, de acordo com a via de parto, no período de 1993 a 2008. 


\section{Lista de figuras}

Figura 1 Curva ROC para a idade gestacional de

página nascimento na predição de complicações

materna puerperais em gestação gemelar.

Área sob a curva =0,61 (IC95\% 0,51 a 0,71). 48 
Stach, SCL. Fatores preditivos de morbimortalidade materna nos partos de gestação gemelar [dissertação]. São Paulo: Faculdade de Medicina. Universidade de São Paulo; 2012.

A melhor via de parto para o nascimento de gestações gemelares permanece controverso. Existe pouca informação na literatura sobre as complicações puerperais maternas destas gestações. O objetivo deste estudo foi avaliar as complicações puerperais maternas de acordo com a via de partos em gestações gemelares e estabelecer fatores de risco associados. Métodos: trata-se de estudo retrospectivo do parto de gestações gemelares, ocorridas no Hospital das Clínicas da Faculdade de Medicina da Universidade de São Paulo, entre 1993 a 2008, com idade gestacional superior a 26 semanas. As vias de parto definidas foram: parto vaginal, cesárea eletiva e cesárea urgente. Gestações com gêmeos unidos ou partos combinados não foram incluídas na análise. A análise multivariada foi realizada para a determinação de fatores preditivos de complicação materna. Os riscos relativos e intervalos de confiança 95\% (ic95\%) foram calculados. Resultados: foram observadas 90 complicações maternas em 56/ 817 (6.9\%) partos, sendo: $7 / 131$ (5,3\%) após parto vaginal, 10/251 (4,0\%) após cesárea eletiva e 10/251 (9,0\%) após cesárea urgente $(p=0,03)$. As complicações maternas foram significativamente associadas com gestações de alto risco $(r=0,16, p<0.001)$, idade gestacional do parto $(r=-0,09, p=0.01)$ e via de parto $(r=0.05, p=0.13)$. A melhor fórmula foi descrita como $0.286+(0.018$ * via de parto $)$ - $(0.008$ * idade gestacional do parto $)+(0.104 *$ gestação de alto risco) $(r=0.20)$. A predição de complicações maternas pela idade gestacional de nascimento mostrou uma área sob a curva ROC de 0,61 (ic95\%=0,51$0,71)$. A análise de risco relativo revelou que foram significativos os partos realizados abaixo de 32sem, com risco relativo(RR) de 1,82 (IC95\%: 1,03$3,29)$, abaixo de 33sem, RR 1,82 (IC95\%:1,06-3,08) e a gestação de alto risco , $R R=3,29$ (IC95\%: 1,99-5,36). A presença de complicações puerperais foi maior após uma cesárea urgente, quando comparada com a cesárea eletiva , $R R=2,34$ (IC95\%:1,21-4,57). Conclusão: complicações puerperais maternas estão relacionadas com gestação de alto risco, partos em idade gestacional precoce e cesarianas urgentes.

Descritores: 1.Gestação gemelar 2. Parto 3. Parto vaginal 4. Cesárea 5. Complicações puerperais . 
Stach, SCL. Risk factors for maternal postpartum complications in twin deliveries [dissertation]. São Paulo: "Faculdade de Medicina, Universidade de São Paulo"; 2012.

The optimal route of delivery of twin gestations is a matter of controversy. There is a lack of data in literature regarding maternal delivery complications in these pregnancies. The objective of this study is to examine maternal postpartum complications according to delivery mode in twin pregnancies and investigate associated factors. Methods: retrospective review of all twin pregnancies, with more than 26 weeks gestational age, that delivered between 1993 and 2008 at Hospital das Clínicas, São Paulo University Medical School. Delivery mode subgroups were defined as: vaginal, elective and emergency cesarean sections. Pregnancies with conjoined twins and combined deliveries were not included in the analysis. Stepwise regression analysis was used to investigate significant predictors of maternal postpartum complications. Relative risks and 95\% confidence intervals were calculated. Results: Ninety maternal pospartum complications were observed in 56/817 (6.9\%) deliveries: $7 / 131$ (5.3\%) vaginal, 10/251 $(4.0 \%)$ elective cesarean sections and 39/435 (9.0\%) emergency cesareans $(p=0.03)$. Maternal complications were significantly associated with high-risk pregnancies $(r=0.16, p<0.001)$, gestational age at birth $(r=-0.09, p=0.01)$, and mode of delivery $(r=0.05, p=0.13)$. The best-fit formula was described by $0.286+(0.018 *$ mode of delivery $)-\left(0.008{ }^{*}\right.$ gestational age at delivery $)+$ $(0.104 *$ high-risk pregnancy) $(r=0.20)$. Prediction of maternal complications according to gestational age at delivery demonstrated an ROC curve area of 0.61 (95\% confidence interval $\mathrm{Cl}=0.51-0.71)$. The likelihood of complications was increased for deliveries before 32 weeks $(R R=1.86$, $95 \% \mathrm{Cl}=1.03-3.29)$, before 33 weeks $(\mathrm{RR}=1.82,95 \% \mathrm{Cl}=1.06-3.08)$ and for high-risk pregnancies $(\mathrm{RR}=3.29,95 \% \mathrm{Cl}=1.99-5.36)$. Occurrence of complications was significantly increased in emergency cesarean compared to elective sections $(\mathrm{RR}=2.34,95 \% \mathrm{Cl}=1.21-4.57)$.Conclusion: Maternal postpartum complications in twin pregnancies are related to preexisting complications, earlier gestational age and emergency cesarean deliveries Keywords: Twin pregnancy 2.Delivery 3. Vaginal delivery 4. cesarean section 5. Puerperal complication. 


\section{1 - Introducãão}

A gestação múltipla é resultado do desenvolvimento de mais de um zigoto ou da divisão de um mesmo zigoto dentro do organismo materno, independente do número final de neonatos, zigotos esses que podem ter sido frutos de um ou mais ciclos ovulatórios ${ }^{(1)}$.

A incidência de gestação gemelar tem crescido mundialmente. Assim, por exemplo, nos Estados Unidos, houve aumento na taxa de nascimento de gestações gemelares da ordem de $52 \%$, entre 1980 e $1997^{(2,3,4)}$, e, no Brasil, foi de 15,7/1000 nascidos vivos, em 1994, para 19/1000 nascidos vivos em $2009^{(5)}$.

Esse aumento se deve, em grande parte, ao uso de técnicas de reprodução assistida (relacionado ao uso de agentes indutores da ovulação) e pelo fato de mulheres postergarem a gestação até idades mais avançadas $(4,6,7)$

As gestações gemelares apresentam maior morbidade. Estão implicadas em maior risco de pré-eclâmpsia (risco relativo 2,6), rotura prematura de membranas (cerca de duas vezes mais frequente), anomalias na placenta e no cordão (gemelares tem $40 \%$ maior de risco de placenta prévia e o dobro de risco de descolamento prematuro de placenta), restrição de crescimento intra-uterino (risco 10 vezes maior), prematuridade (cerca de $50 \%$ dos gemelares nascem prematuros), malformação fetal (risco 5 a 6\% maior), morte materna (risco de 2 a 4 vezes maior) e perinatal (risco 5 a 6 vezes maior) ${ }^{(8,9,10,11,12,13,14,15,16)}$.

O baixo peso ao nascimento e a prematuridade são os grandes responsáveis pela morbimortalidade nessas gestações. Blondel et al ${ }^{(9)}$, estudando a prematuridade, no Continente Europeu, observam que a gravidez múltipla é responsável por 18 a $25 \%$ da taxa de prematuros de cada país. Mathews e MacDorman ${ }^{(17)}$ notam que apesar de gestações gemelares representarem aproximadamente $3 \%$ dos nascimentos ocorridos 
nos Estados Unidos, em 2004, são responsáveis por cerca de $15 \%$ dos casos de morte perinatal. Assim, gestações gemelares têm risco cinco vezes maior de morte perinatal quando comparadas com gestações de feto único.

O parto em gestações gemelares é um evento de risco. Problemas relacionados a ele também influenciam a morbidade e a mortalidade. A melhor via de parto para gestações gemelares tem sido motivo de controvérsia na literatura médica. Existem três modos de nascimento em gestações gemelares: ambos podem nascer de parto vaginal, ambos podem nascer de parto cesárea ou um parto combinado, em que o primeiro gemelar nasce de parto normal e o segundo, de cesárea. O último modo ocorre, aproximadamente, em 9,5\% das gestações inicialmente programadas para o parto normal ${ }^{(18)}$ e está associado à maior morbidade e mortalidade neonatal ${ }^{(18,19,20,21)}$

Em gestações únicas, a via de parto é influenciada pela apresentação fetal, o que também ocorre em gestações múltiplas.

Assim, de acordo com o "American College of Obstetrician and Gynecologists" (ACOG) ${ }^{(22)}$ de 1999, a via de parto preferencial, em gestações gemelares com apresentação cefálica/cefálica, seria o parto vaginal. Nas gestações em que o primeiro gemelar for não cefálico, o ACOG (22) recomenda a cesariana. Nas gestações gemelares em que a apresentação for cefálica/não cefálica, a via de parto é bastante controversa. De acordo com o ACOG ${ }^{(22)}$, o parto normal pode ser tentado, desde que o peso dos fetos seja maior que $1500 \mathrm{~g}$ e não exista contraindicação. Em 2000, a "Society of Obstetricians and Gynecologists of Canada" (SOGC) ${ }^{\text {(23) }}$ recomenda o parto vaginal se o peso estimado estiver entre 1500 e $4000 \mathrm{~g}$. Mas Yang et al ${ }^{(24)}$ observam menor morbidade e mortalidade se, nesse grupo, for feito parto cesáreo eletivo.

Alguns estudos recentes realizados por Armson e Smith (25,26,27) sugerem, contudo, a vantagem do parto cesáreo para todas as gestações gemelares, independente da apresentação fetal, como estratégia para melhorar os resultados perinatais. Assim, eles observam que, em gestações gemelares de termo, o segundo gemelar tem maior risco de morte quando 
comparado com o primeiro, e, em $75 \%$ das vezes, a causa seria a anóxia. Consequentemente, o parto cesáreo planejado poderia ajudar a diminuir esse risco. Entretanto, uma metanálise de Hoogle et al ${ }^{(28)}$, em 2003, não identifica evidências que suportem a política de cesárea eletiva para todas as gestações gemelares, embora a autora observe que o parto cesáreo planejado diminui o risco de Apgar de quinto minuto baixo, especialmente se o primeiro feto for pélvico .

A literatura oferece evidência de que as complicações puerperais, após gestação gemelar, são maiores que após gestação única, independente da via de parto. Assim, alguns autores relatam maior incidência de hemorragia puerperal, morbidade febril puerperal, histerectomia (HTA), admissão em unidade de terapia intensiva (UTI), fenômenos tromboembólicos e morte materna em gestações múltiplas $(29,30,31,32,33,34,35)$

A incidência de partos cesáreos tem crescido mundialmente, tanto em gestações únicas como múltiplas. Sua incidência em gestações gemelares apresentou aumento, nos Estados Unidos, de 53,4\%, em 1995, para 75,0\%, em $2008^{(36)}$.

Estudos realizados em gestações únicas revelam que a cesárea pode estar implicada em maior taxa de complicação puerperal, como complicações de ferida cirúrgica, histerectomia, infecção puerperal, tromboembolismo e maior tempo de internação hospitalar $(33,34,37,38,39,40,41,42,43,44,45,46)$.

Alguns estudos revelam que a cesárea pode inclusive aumentar 0 risco de complicações em uma gestação futura. Assim, mulheres submetidas a ela parecem ter maior risco de histerectomia, nas próximas gestações, pois a cesariana pode aumentar a chance de alterações na placentação $(47,48,49,50,51)$.

Estudos em gestações únicas também demonstram que a cesárea urgente tem maio risco de complicações que a eletiva. Assim, a cesárea urgente estaria implicada em maior risco de infecção de ferida cirúrgica, endometrite, perda sanguínea e taxa global de complicações ${ }^{(38,41,52,53,54)}$. 
Poucos estudos incluíram a gestação múltipla para avaliar a influência da via de parto na morbidade materna. Em gestações gemelares, alguns autores relacionam o parto cesáreo a um maior risco de morbidade puerperal, tais como fenômenos tromboembólicos, infecção, hemorragia e histerectomia $(35,55,56,57,58)$. Entretanto, outros estudos não observam o aumento de morbidade materna relacionado à via de parto ${ }^{(28,59,60)}$.

Tendo em vista a controvérsia, na literatura, envolvendo a via de parto em gestações gemelares e a escassez de dados sobre a morbidade puerperal relacionada à via de parto, a proposta deste trabalho é estudar os resultados maternos dessas gestações de acordo com a via de parto realizada. O esclarecimento sobre as questões relacionadas à via de parto dessas gestações pode auxiliar no manejo futuro das gestações múltiplas. 


\section{2 - Objetivos}

O presente estudo em gestações gemelares tem como objetivos:

- descrever a frequência de complicações maternas após o parto;

- investigar a influência da via de parto na frequência dessas complicações;

- examinar a relevância de outros fatores preditivos na ocorrência de complicações maternas. 


\section{3 - REVISÃO DE LITERATURA}

\subsection{Dados estatísticos de gestações múltiplas e estatísticas de parto}

Sabe-se que, desde 1970, a frequência de gestações gemelares tem crescido, após ter apresentado um período de queda que se iniciou por volta de 1900. Nos Estados Unidos, houve aumento na taxa de nascimento de gestações gemelares de $52 \%$ entre 1980 e 1997 . Em 1980, essa taxa era de $18,9 / 1000$ nascidos vivos e, em 1997 , foi de $26,8 / 1000$ nascidos vivos ${ }^{(2,3,4)}$.

O Continente Europeu também apresentou aumento na taxa de gestações gemelares, mas isso variou entre os diferentes países. Assim, entre 1975 e 2002, houve aumento na taxa de gemelares, em torno de 50\%, na Inglaterra, e 90\%, na Holanda. Assim, no ano de 2000, a taxa de gemelares / 1000 nascidos vivos foi de 12,3, na Itália, e 19,4, na Holanda ${ }^{(9)}$.

No Brasil, segundo o Ministério da Saúde, em 1994, a taxa de gemelares era de 15,7/1000 nascidos vivos e, em 2009, de 19/1000 nascidos vivos ${ }^{(5)}$.

A incidência de cesáreas também tem apresentado crescimento, tanto em gestações únicas como em múltiplas ${ }^{(36,61,62,63)}$. Assim, a taxa de cesárea, nos Estados Unidos, cresceu de 20,7\%, em 1996, para 32,9\%, em $2009^{(61)}$. Nesse país, a incidência de partos cesáreos em gestações gemelares apresentou aumento de 53,4\%, em 1995, para 75,0\%, em 2008 (36). A América Latina registrou uma taxa média de cesárea de 33\% em 2005 ${ }^{(63)}$. No Brasil, em 2010, a taxa de partos cesárea foi de 52,3\%, sendo 51,8\% em gestações únicas e $78,7 \%$ em gestações gemelares ${ }^{(5)}$. No Brasil, a taxa de partos cesáreos para gestações gemelares foi de 52,1\%, em 1995, para $78,7 \%$, em $2010^{(5)}$.

Muitos fatores têm sido relacionados com o aumento na incidência de cesarianas, entre elas, a melhoria nas técnicas anestésicas e cirúrgicas, os 
avanços na antibioticoterapia profilática, a redução na taxa de complicações puerperais, a percepção do baixo risco do procedimento pela classe médica e público leigo e a demanda espontânea das pacientes por um parto cesáreo (64).

Vários fatores têm sido implicados no aumento da incidência de cesarianas em gestações múltiplas. Hannah et al ${ }^{(65)}$ publicam um estudo multicêntrico randomizado, em 2000, ("Breech Trial") em que demonstram a melhoria dos resultados perinatais em gestações de feto único pélvico quando a via de parto foi a cesariana, sem a elevação dos riscos maternos. Assim, muitos autores passam a questionar o parto vaginal em gestações gemelares em que pelo menos um feto se encontra na posição pélvica. Entretanto, Lee et al ${ }^{(36)}$, analisando o aumento da incidência de partos cesáreos em gestações múltiplas, nos Estados Unidos, observam que as razões para isso não podem ser explicadas apenas pela presença de pelo menos um dos gemelares em apresentação pélvica. Kogan et al ${ }^{(66)}$, analisando os dados do Centro Nacional Americano de Estatísticas da Saúde, concluem que, no período de 1981 a 1997, o aumento da intervenção obstétrica (indução de parto e partos cesáreos) em gestações gemelares ocasiona aumento na taxa de partos prematuros. Mas isso resulta na diminuição da taxa de mortalidade perinatal. Outros autores concordam que o aumento da intervenção obstétrica está associado à diminuição nas taxas de óbito intraútero e mortalidade perinatal ${ }^{(67)}$.

\subsection{VIA DE PARTO}

A escolha da melhor via de parto em uma gestação gemelar é motivo de controvérsia na literatura.

Assim como a gestação gemelar é uma situação de risco, o parto, nessas gestações, também apresenta aumento de morbidade. $O$ nascimento do segundo gemelar apresenta desafios únicos decorrentes de complicações que podem ocorrer após o nascimento do primeiro como, por 
exemplo, o prolapso de cordão, o sofrimento fetal, o descolamento prematuro da placenta e anóxia, expondo, assim, o segundo a um aumento de morbidade. Para esclarecer esse tópico vários trabalhos foram realizados, como estudos retrospectivos hospitalares, estudos populacionais e um único estudo randomizado de pequeno porte.

Para esclarecer a melhor via de parto em gestações gemelares, o Instituto Canadense de Pesquisa em Saúde ${ }^{(68)}$ iniciou, em 2003, o estudo de parto de gemelares ("Twin Birth Study"). Trata-se de um estudo prospectivo randomizado multicêntrico que seguirá 2800 gemelares, entre 32 a 38 semanas de gestação, que serão randomizados para um parto cesáreo ou vaginal programado.

Atualmente, a escolha da via de parto baseia-se na apresentação fetal e peso dos fetos ${ }^{(69,70,71)}$.

A apresentação fetal intraparto divide-se em:

- cefálica / cefálica, em $42,5 \%$.

· cefálica / não cefálica, em 38,4\%.

-primeiro gemelar não cefálico, em $19,1 \%{ }^{(69)}$.

Existem alguns pontos importantes a serem levados em conta ao se analisar a melhor via de parto para as gestações gemelares ${ }^{(72)}$ :

-Primeiramente, nem todos os médicos são treinados para realizar um parto vaginal em gestações gemelares. Isso porque, nelas, em 50 a $60 \%$ das vezes, um dos fetos estará em posição não cefálica, necessitando assim de um parto assistido e de uma equipe médica com experiência. Após o estudo canadense realizado em gestações únicas de termo com fetos em apresentação pélvica demonstrar a superioridade da cesariana nessas situações, muitas instituições estenderam essa conclusão para as gestações gemelares.

·Em muitas gestações gemelares, existe a chance de a parturiente já ter tido um parto cesáreo anterior, o que, para muitos obstetras, designa contra indicação para o parto vaginal. 
- Muitas gestações gemelares são fruto do uso de técnicas de reprodução assistida, podendo levar muitas pacientes a rejeitar a ideia de um parto via vaginal em uma gestação sobrevalorizada.

-Em muitas gestações gemelares ocorre prematuridade, levando ao nascimento de neonatos menores e com baixo peso ou muito baixo peso. Nessas situações, o parto vaginal, para a maioria dos autores, está contraindicado.

-Gestações gemelares estão implicadas em maior incidência de doença materna, o que, embora possa não ser uma indicação absoluta para o parto cesárea, pode ser um fator de risco para o aumento de morbidade e mortalidade materna e neonatal.

- O parto do segundo gemelar pode estar relacionado a maior risco de asfixia devido ao intervalo de nascimento entre os fetos, ao prolapso de cordão umbilical, à separação das placentas, ao comprometimento da perfusão placentária e à apresentação anômala.

\section{$\underline{\text { Primeiro e segundo gemelares cefálicos }}$}

Em gestações em que ambos os fetos são cefálicos, a literatura apoia o parto via baixa. Assim, o ACOG ${ }^{(73)}$ e a SOGC ${ }^{(23)}$ estabelecem que o parto vaginal é a via preferencial de nascimento, desde que não haja contraindicações. A maioria dos autores concorda com essa afirmação.

Peaceman et al (74) analisam 405.504 gemelares nascidos nos Estados Unidos, entre 1995-2000, com idade gestacional >30 semanas, peso > 1500 gramas em que o primeiro é cefálico. Os gemelares são divididos em dois grupos, sendo o primeiro composto por aqueles na apresentação cefálico/cefálico e o segundo, cefálico/não cefálico. Eles observam que para fetos cefálicos / cefálicos a via de parto não influencia a morbidade (definida como Apgar de quinto minuto <3, convulsão e trauma de parto) e mortalidade no primeiro ano de vida . 
Kontopoulos et al ${ }^{(20)}$, em um estudo retrospectivo com 88.811 gestações, analisam o impacto da via de parto e da apresentação fetal na morte neonatal e infantil de gemelares nascidos com idade gestacional >34 semanas, com o primeiro gemelar em apresentação cefálica. Observam que, nas apresentações cefálica/cefálica, o parto vaginal apresenta menor taxa de mortalidade que o parto cesáreo. O maior risco de morte ocorre quando a via de parto foi o combinado.

Entretanto, estudos populacionais mostram que os resultados perinatais do segundo gemelar podem estar comprometidos quando a via de parto é vaginal. Yang et al ${ }^{(75)}$ realizam um estudo retrospectivo em que são analisados os resultados neonatais do segundo gemelar, em 86041 gestações com apresentação cefálica/cefálica, de acordo com a via de parto e peso fetal. Os dados são coletados do arquivo de partos múltiplos americano dos anos de 1995-1997. São incluídos os casos de nascidos vivos com peso $>500 \mathrm{~g}$ e idade gestacional $>24$ semanas. A população é dividida em 3 grupos: os nascidos de parto cesáreo (43\%), vaginal $(53,5 \%)$ ou combinado (3,5\%). Os autores concluem que o risco de morte e morbidade neonatal (Apgar $5^{\circ}$ minuto $<3$, necessidade de ventilação mecânica e convulsão) é aumentado no segundo gemelar com peso $>2500 \mathrm{~g}$, quando o primeiro nasce de parto vaginal se comparado com aqueles em que o primeiro gemelar nasce de parto cesariano.

\section{$\underline{\text { Primeiro gemelar cefálico e segundo gemelar não cefálico }}$}

Existe muita controvérsia na literatura médica sobre a melhor via de parto nessa situação. Após o "Breech Trial" (65) (um estudo prospectivo randomizado que estuda a melhor via de parto para gestações com fetos únicos pélvicos) concluir que o parto cesáreo apresenta melhores resultados perinatais sem aumento da morbidade materna, muitos autores passam a questionar a melhor via de parto em gestações gemelares em que pelo menos um feto não é cefálico. O ACOG ${ }^{(73)}$ admite que os dados de literatura 
são conflitantes e orienta que o parto vaginal pode ser tentado se o peso dos fetos for superior a $1500 \mathrm{~g}$.

Rabinovic et al ${ }^{(56)}$, no único estudo randomizado, na literatura, a esse respeito, comparam os resultados maternos e neonatais, de acordo com a via de parto, para nascimentos após 35 semanas. O primeiro gemelar apresenta melhor Apgar de primeiro minuto que o segundo, independente da via de parto. Não há diferenças nos resultados neonatais, de acordo com a via de parto, mas a morbidade febril puerperal foi maior nas pacientes submetidas ao parto cesáreo .

Yang et al ${ }^{(24)}$ realizam um estudo populacional retrospectivo baseado no nascimento de todos os gemelares nos Estados Unidos entre 1995-1997. Estudam a morbidade (trauma de parto, Apgar $5^{\circ}$ minuto $<7$, ventilação mecânica e convulsão) e mortalidade no segundo gemelar nascido vivo na apresentação cefálica/não cefálica, de acordo com a via de parto. A análise é restrita aos casos com apresentação cefálica/não cefálica, com IG >24 semanas e peso>500g, totalizando assim 15.185 partos. Eles dividem a via de parto em vaginal $(46,8 \%)$, cesárea $(37,7 \%)$ ou combinado $(15,5 \%)$. O risco de morte por asfixia neonatal e morbidade neonatal é maior naqueles nascidos de parto vaginal e parto combinado quando comparado com o parto cesáreo. O aumento do risco de morte neonatal nos nascidos de parto vaginal é maior no grupo com peso $<1500 \mathrm{~g}$. Já o aumento da morbidade neonatal observado no grupo de parto vaginal e parto combinado é mais importante nos recém-nascidos que apresentam peso entre $1500 \mathrm{~g}$ a $4000 \mathrm{~g}$.

Peaceman et al ${ }^{(74)}$, analisando 40.5504 gemelares nascidos nos Estados Unidos, entre 1995-2000, com idade gestacional >30 semanas e peso >1500 g, notam que, em apresentações cefálica/não cefálica, o parto vaginal é responsável por um aumento na incidência de Apgar de $5^{\circ}<3$ e trauma de parto. 


\section{$\underline{\text { Primeiro gemelar não cefálico }}$}

Atualmente a via de parto de escolha, nessa situação, é o parto cesáreo, recomendado pelo ACOG ${ }^{(73)}$. Nessa apresentação existe o risco de encravamento de cabeças. É um fenômeno raro, cuja frequência gira em torno de 1/645 partos de gemelares, porém com altas taxas de mortalidade, entre 30 a $43 \%{ }^{(71)}$. Após o "Breech Trial" ter demonstrado que o parto cesáreo oferece menor risco para o feto único pélvico sem o aumento de morbidade materna, a maioria dos autores concorda que o parto cesárea é mais seguro nessa situação.

\subsection{MORBIDADE PUERPERAL E MORTALIDADE MATERNA}

Vários estudos analisam morbidade puerperal, nas diferentes vias de parto, em uma gestação única, mas poucos trabalhos existem, na literatura médica, sobre o risco de morbidade e mortalidade materna associado à via de parto em gestações gemelares.

- Morbimortalidade materna em gestações únicas de acordo com a via de parto

Diversos estudos foram realizados para investigar as complicações pós-parto maternas de acordo com a via de parto em gestações únicas.

Alguns estudos retrospectivos populacionais demonstram aumento de morbidade em pacientes submetidas à cesárea quando comparadas àquelas submetidas a parto vaginal.

Allen et al ${ }^{(76)}$, num estudo populacional retrospectivo, no Canadá, comparam a morbidade materna em partos de termo realizados por via vaginal e via cesariana fora de trabalho de parto. O grupo de parto vaginal é composto por 17.714 nuligestas com uma gestação única cefálica de termo. 
Apenas 721 pacientes representam o grupo de cesárea fora de trabalho de parto (constituído, em sua maioria, por gestações únicas com feto pélvico). Pacientes com complicações obstétricas ou doença materna pré-existente são excluídas da análise. Os autores concluem não haver diferença na taxa global de morbidade puerperal entre as duas vias de parto. Entretanto, as pacientes submetidas à cesariana têm maior incidência de morbidade febril puerperal, mas uma menor taxa de hemorragia puerperal. Não há diferença na taxa de infecção de ferida cirúrgica, transfusão de sangue ou trauma intraoperatório.

Liu et al ${ }^{(37)}$ estudam a morbidade materna grave e mortalidade pósparto, de acordo com a via de parto planejado. Para isso, realizam um estudo retrospectivo populacional, no Canadá, envolvendo 46.766 mulheres no grupo de cesárea planejada e 2.292.429 mulheres no grupo de parto vaginal programado. O grupo de cesárea programada é composto por mulheres com gestações com feto único pélvico. Observam que a taxa de complicações no grupo de cesárea programada é de $27,3 \%$ contra $9,0 \%$ no grupo de parto vaginal programado (razão de chance de 3,1). Assim, o primeiro grupo tem maior risco de parada cardíaca, hematoma cirúrgico, HTA, infecção puerperal, complicações anestésicas, tromboembolismo venoso e maior permanência hospitalar. Entretanto, essas pacientes apresentam menor risco de hemorragia, necessitando de sangue e de rotura uterina. O risco de morte materna é semelhante nas duas vias de parto. Embora o grupo de cesariana planejada apresente maior risco de complicações maternas graves do que o de parto vaginal planejado, as diferenças absolutas na incidência de complicações são pequenas.

Wax ${ }^{(77)}$ realiza uma revisão de literatura para estudar a morbidade puerperal, de acordo com a via de parto planejada. O autor observa que os dados analisados sugerem que tanto o parto vaginal planejado como a cesárea planejada apresentam riscos similares e baixos de complicações puerperais. O segundo apresenta maior frequência de endometrite e de cistite, enquanto o primeiro, de hemorragia. Grande parte da morbidade apresentada pelo grupo de parto vaginal programado é representada pelo 
grupo de cesariana não planejada realizada intraparto e pelo de parto vaginal operatório. Assim, a frequência de complicação puerperal nos grupos de parto vaginal e cesárea planejados vai depender da frequência de pacientes que apresentam o parto realizado de acordo com a via de parto programada.

O Departamento Americano de Saúde e Serviços Humanos ${ }^{(62)}$ faz, em 2006, uma revisão de literatura sobre os riscos e benefícios da cesariana em relação ao parto vaginal para esclarecer o tópico cesárea a pedido materno. Observa-se evidência moderada na literatura médica (nível 2) de que a frequência de hemorragia puerperal que ocorre após uma cesariana planejada é menor do que após uma cesariana urgente em um parto vaginal planejado. Também há evidências, na literatura de nível 2, de que o tempo de internação materna é maior no grupo de cesárea (planejado ou não) quando comparado com o grupo de parto vaginal. Existem resultados maternos que apresentam evidências fracas ( nível 3 ), na literatura, que favorecem ora o parto vaginal ora a cesariana. Essas conclusões estão listadas a seguir. A taxa de infecção é menor após um parto vaginal programado quando comparado com a cesariana programada, que, por sua vez, teria menor risco de infecção que a cesárea urgente. O risco de placenta prévia em gestações futuras estaria aumentado após uma cesariana. Por sua vez, o risco de complicações cirúrgicas é menor na cesariana programada que na cesárea urgente resultante de um parto vaginal programado. $O$ risco de rotura uterina é maior na paciente submetida a um parto vaginal programado, após uma cesariana, que naquela paciente submetida a outra cesariana eletivamente. $O$ risco de histerectomia é maior em pacientes com várias cesarianas anteriores e parece ser o mesmo, após uma primeira cesárea planejada e após um parto vaginal programado.

O estudo randomizado mais recente que compara a morbidade entre as vias de parto é publicado por Hannah et al ${ }^{(65)}$. Trata-se de um estudo multicêntrico com 2088 mulheres para estudar a melhor via de parto em pacientes com gestação única com o feto em apresentação pélvica. Assim, são comparados o grupo de cesárea planejada com o de parto vaginal 
programado. Não há diferença entre os grupos com relação à mortalidade materna ou morbidade materna grave.

Um estudo retrospectivo realizado no Hospital das Clínicas da Faculdade de Medicina da Universidade de São Paulo (HCFMUSP), em 2004, compara as complicações maternas, de acordo com a via de parto, em 1748 gestações únicas. Há $56,5 \%$ de cesáreas e $43,5 \%$ de partos vaginais. Os dados coletados versam acerca de complicações no parto e as puerperais que necessitam de nova intervenção (complicações infecciosas e hemorrágicas). Concluem não haver diferença estatisticamente significante na taxa de complicação puerperal, de acordo com a via de parto ${ }^{(78)}$.

Existem diversos estudos populacionais para investigar a influência da via de parto em complicações puerperais pouco comuns, como a mortalidade materna, a histerectomia puerperal e o tromboembolismo .

Assim, diversos estudos sobre a influência da via de parto na mortalidade materna são realizados. Kamilya et al ${ }^{(38)}$, em 2000 , realizam um levantamento retrospectivo coorte para avaliar o risco de morte materna diretamente associado aos partos cesariana e vaginal em um hospital na Índia. Para isso, são excluídas pacientes com comorbidades obstétricas ou clínicas. Há 27 mortes entre as 13.627 pacientes submetidas à cesárea (2,0/1000 pacientes) e 19 mortes em 30.215 que tiveram parto vaginal (0,6/1000 pacientes). Os autores concluem que o parto cesáreo aumenta em 3,01 vezes o risco de morte quando comparado ao parto vaginal. Isso é resultado principalmente do aumento de risco por complicações anestésicas, infecção puerperal e tromboembolismo venoso. O risco de morte por hemorragia é semelhante nas duas vias de parto. Entretanto, ao comparar as mortes ocorridas em cesáreas realizadas anteparto com as intraparto, concluem que o risco de morte é aumentado apenas para as cesáreas realizadas intraparto.

Em 2001, Lydon Rochelle et al (79) apresentam um estudo populacional retrospectivo, realizado em Washington, para determinar a associação entre a via de parto e a morte materna em primíparas com gestação única. Em até 6 meses pós-parto, há 32 mortes $(12,1 / 100.000$ 
nascimentos), sendo 11 relacionadas diretamente ao parto. Inicialmente, a análise mostra que, após a cesárea, o risco de morte é aumentado (10,3/100.000 após a cesariana versus 2,3/100.000 após o parto vaginal), mas, após a regressão logística, esse risco deixa de ser significante. Os autores concluem que o parto cesáreo é mais um marcador de morbidade grave que elevaria o risco de morte materna do que um fator de risco "per se".

Em 2006, Deneux Tharaux et al ${ }^{(39)}$, num estudo populacional casocontrole, analisam a influência da via de parto no risco de morte materna na França. As mortes ocorridas devido a morbidades antenatais são excluídas. As pacientes com internação na gestação estudada também são excluídas. Há 65 casos e os controles são compostos por 10.224 pacientes. Os autores concluem que o risco de morte é 3,6 vezes maior após uma cesárea quando comparado com o parto vaginal, risco aumentado tanto nas cesáreas anteparto como nas intraparto. As mortes são causadas principalmente por complicações anestésicas, infecção puerperal e tromboembolismo venoso. O risco de morte por hemorragia é semelhante nos dois grupos.

De fato, o Instituto Nacional de Saúde Americano ${ }^{(62)}$, ao estudar o tema cesárea a pedido materno, analisa os benefícios e danos relacionados a um parto cesáreo programado. O consenso conclui que os estudos existentes na literatura médica que avaliam a influência da via de parto na incidência da mortalidade materna são inconclusivos.

Diversos estudos analisam a influência da via de parto na incidência de histerectomia. Em gestações únicas, os dados confirmam o aumento do risco de histerectomia puerperal após a cesárea. As principais causas de histerectomia puerperal são a adesão placentária irregular, a atonia uterina e a rotura uterina. A cesária também está implicada em aumento de risco de histerectomia em gestações subsequentes. Assim, além de a cesárea ser um fator de risco intrínseco para HTA, também predispõe a uma placentação anormal em gestações futuras, aumentando, assim, o risco de HTA em gestações subsequentes ${ }^{(47,48,49,50,51)}$. 
Em 2007, Yang et al ${ }^{(80)}$, num estudo retrospectivo populacional, avaliam a associação entre a realização de uma cesariana, na primeira gestação, com o risco de desenvolvimento de placenta prévia (PP) ou de descolamento prematuro de placenta (DPP) na gestação subsequente. As pacientes são portadoras de uma segunda gestação com feto único. $O$ estudo conclui que a cesárea, na primeira gestação, aumenta o risco de PP em $47 \%$ e de DPP em $40 \%$, quando comparada com um parto vaginal na primeira gestação. Assim, o risco de PP, em uma segunda gestação, após cesárea na primeira gestação, é de 4,4/1000 nascimentos versus 2,7/1000 nascimentos nas pacientes submetidas a parto vaginal na primeira gestação. Já o risco de DPP nas pacientes que tiveram um parto cesárea na primeira gestação é de 6,8/1000 nascimentos versus 4,8/1000 nascimentos naquelas pacientes submetidas a um parto vaginal na primeira gestação.

Outros estudos em gestações únicas mostram que a cesárea pode ser um fator de risco para admissão em UTI ${ }^{(44)}$ e readmissão hospitalar ${ }^{(45)}$.

Alguns estudos, na literatura, avaliam a influência da via de parto na incidência de fenômenos tromboembólicos. Várias publicações revelam que o risco de fenômenos tromboembólicos é aumentado após uma cesárea.

Assim, Lindqvist et al ${ }^{(81)}$, em 1999, em um estudo populacional, na Suécia, avaliam a incidência e fatores de risco para o tromboembolismo na gestação. Eles observam que pacientes submetidas a um parto cesáreo têm aumento de cinco vezes no risco de fenômenos tromboembólicos quando comparadas com as submetidas a um parto vaginal. Simpson et al ${ }^{(34)}$, em 2001, em um estudo caso-controle, em uma maternidade, em Londres, observam a ocorrência duas vezes maior de tromboembolismo venoso no puerpério do que no período gestacional. A gestação múltipla é um fator de risco antenatal, enquanto a cesárea, um fator de risco pós-natal para o tromboembolismo. Jacobsen et al ${ }^{(33)}$ conduzem outro estudo caso-controle, na Noruega, para identificar a incidência e fatores de risco para o tromboembolismo na gestação e no puerpério. Os autores observam que a incidência de tromboembolismo venoso é semelhante ante e pós-natal. Um dos fatores de risco antenatal identificado é a gestação múltipla, enquanto a 
cesárea seria um fator de risco pós-natal. Outros autores também observam aumento de risco de tromboembolismo associado à cesárea ${ }^{(82,83)}$. Lanska e Kryscio ${ }^{\left({ }^{84}\right)}$ realizam um estudo populacional americano para pesquisar fatores de risco associados ao acidente vascular cerebral (AVC) e à trombose venosa intracraniana periparto e pós-parto. Os autores concluem que a cesárea implica em aumento significante destas patologias.

Morbimortalidade materna em gestações gemelares versus gestações únicas

A literatura oferece evidência de que as complicações puerperais, após uma gestação gemelar, são maiores que após uma gestação única, independente da via de parto.

Assim, Conde-Agudelo et al ${ }^{\left({ }^{(5)}\right)}$ estudam a associação entre gestação gemelar e resultados maternos adversos. São analisadas 885.338 gestações, sendo 15.848 múltiplas. Os dados são extraídos do banco de dados do Centro Latino Americano de Perinatologia e Desenvolvimento Humano. Os autores concluem que, quando comparada com gestações únicas, a gemelar aumenta o risco de morte, hemorragia pós-parto, eclâmpsia, parto prematuro, endometrite, infecção urinária e parto cesárea.

\section{-Hemorragia puerperal}

No mesmo estudo de Conde Agudelo et al ${ }^{(85)}$, é observado que gestações gemelares têm risco duas vezes maior de hemorragia puerperal que gestações únicas.

Suzuki et al ${ }^{(86)}$ num estudo retrospectivo caso-controle com 511 gestações gemelares, em um hospital japonês, analisam fatores de risco para a transfusão de sangue. Os autores observam que esse risco é maior em gestações gemelares que nas únicas. Assim, a transfusão de sangue foi 
realizada em 3,5\% das pacientes com gestações gemelares (18 pacientes) e $0,64 \%$ daquelas com gestação única (60 de 9.306 pacientes). A necessidade de sangue é maior em pacientes que tiveram parto cesáreo eletivo com idade gestacional > 37 semanas. O parto cesáreo de urgência não está associado com a necessidade de transfusão de sangue.

Bateman et al ${ }^{(29)}$ desenvolvem um estudo populacional americano, com 876.641 partos, ocorridos entre 1995 a 2004, para determinar a incidência de hemorragia pós-parto, os fatores de risco e os resultados maternos relacionados com ela. Em 2004, a hemorragia puerperal, cuja principal causa é a atonia uterina, ocorre em 2,9\% dos partos $(25.654$ pacientes). A hemorragia pós-parto é associada com um risco de morte materna de $19,1 \%$. A taxa de hemorragia puerperal aumentou $27,5 \%$ no período de estudo. A regressão estatística revela que os fatores de risco associados com sua incidência foram: idade materna $<20$ ou $>40$ anos, parto cesáreo, hipertensão na gestação, polidrâmnio, corioamnionite, gestação múltipla, retenção placentária e hemorragia anteparto. Outros autores corroboram a conclusão de que a gestação gemelar é um fator de risco para a hemorragia puerperal ${ }^{(30,87)}$.

\section{- Endometrite}

Infecções puerperais são mais comuns em gestações múltiplas do que nas únicas. Assim, Conde Agudelo et al ${ }^{(85)}$ observam aumento significativo de endometrite em gestações gemelares em relação às únicas, com risco relativo 1,8$)$. Já Suonio e Huttunen ${ }^{(32)}$ constatam que o risco de endometrite triplica e o de infecção da ferida cirúrgica dobra após um parto de gestação gemelar, quando comparado a uma gestação única. Para isso eles comparam o parto cesáreo, ocorrido entre 1984-89, de 122 mulheres, com gestação múltipla, com 761 de fetos únicos. A análise multivariada revela que o maior risco de endometrite, após o parto cesáreo de gemelares, 
é ligado à idade materna $<25$ anos e um período $>6$ horas, entre a ruptura de membrana e o nascimento.

- Infecção de ferida cirúrgica

Schneid-Kofman et al ${ }^{(35)}$ também observam aumento no risco de ferida cirúrgica após parto de gêmeos. Assim, realizam um estudo populacional com 19.416 pacientes submetidas à cesariana para tentar determinar os fatores de risco para a infecção de ferida cirúrgica, infecção essa presente em $3,7 \%$ das pacientes. Os fatores de risco associados a essa patologia são: a obesidade, o diabetes, a hipertensão, a ruptura prematura de membranas, a cesárea de urgência e o parto gemelar.

\section{- Histerectomia puerperal}

O risco de histerectomia periparto também parece maior em gestações gemelares. Assim, Knight et al ${ }^{(58)}$ realizam um estudo populacional caso-controle baseado em dados da população inglesa com partos ocorridos entre 2005 e 2006. Seu objetivo é determinar a incidência de histerectomia puerperal e fatores de risco associados. A incidência de histerectomia é de 4,1/1000 partos, e de mortalidade, de 0,6\%. Fatores de risco para a histerectomia são o parto cesáreo anterior, idade materna $>35$ anos, paridade $>3$, remoção manual da placenta em gestação anterior, miomectomia anterior, gestação gemelar e parto cesáreo na gestação atual.

Entretanto, Bodelon et al ${ }^{(88)}$, em um estudo populacional casocontrole americano, não observam aumento no risco de histerectomia relacionado à gemelidade. Os autores realizam um estudo na população de Washington em partos ocorridos entre 1987 e 2006. Seu objetivo é identificar fatores de risco associados à histerectomia periparto (até 30 dias pós-parto). Registram 896 casos. A incidência varia de 0,25/1000 nascimentos, em 
1987, a 0,82/1000 em 2006. Fatores relacionados à hemorragia como placenta prévia, descolamento prematuro de placenta, a placenta retida, a atonia uterina, a ruptura uterina e a trombocitopenia aumentam o risco. Gestações gemelares não aumentam o risco. O parto cesárea na gestação atual e em gestações anteriores aumentam também a chance de uma histerectomia.

\section{·Fenômenos tromboembólicos}

Fenômenos tromboembólicos têm incidência aumentada em gestações gemelares. Simpson et al ${ }^{(34)}$ desenvolvem um estudo para determinar a incidência e fatores de risco do tromboembolismo venoso (TEV) na gestação e no puerpério. Usando dados ingleses, são selecionadas 395.335 mulheres. Sua incidência é de 85/100.000 gestações. Há mais casos puerperais que durante a gestação. Os fatores de risco associados são: tipo sanguíneo $A$, gestação gemelar, cesárea, doença cardíaca, parto com menos de 36 semanas, índice de massa corpórea $>25$ e idade materna $>35$ anos.

Jacobsen et al ${ }^{(33)}$, em um estudo caso-controle norueguês em que são analisadas 613.232 gestações, também observam que a gestação gemelar é um fator de risco antenatal (junto com diabetes gestacional, idade materna > 35 anos, primiparidade e reprodução assistida), enquanto a cesariana é um fator de risco pós-natal (além de DPP, placenta prévia e préeclâmpsia) para a TEV. A incidência de TEV na população estudada é de 1/1000 gestações.

·Admissão em Unidade de Terapia Intensiva

A taxa de admissão em UTI também parece maior em gestações gemelares. Assim, Baskett e O'Connell ${ }^{(89)}$ observam risco relativo de 3,3 de 
transferência para UTI em gestações múltiplas quando comparadas com as únicas. Esse estudo, de 2009, tem por objetivo determinar os fatores de risco associados à admissão materna em UTI. Para isso, são revisados os dados de todas as pacientes admitidas na UTI. Em 24 anos, há 5 mortes maternas e 93 pacientes são admitidas na UTI. A maioria das internações são pós-parto e, em grande parte, associada à presença de hemorragia ou doença hipertensiva. As pacientes com gestação gemelar apresentam maior taxa de admissão em UTI que pacientes com fetos únicos. Senat et al ${ }^{(90)}$ também constatam que a admissão em UTI é maior em gestações gemelares $(3,1 \%)$ do que nas únicas $(0,2 \%)$.

-Morte materna

Existem poucos estudos, na literatura médica, que comparam a taxa de morte materna nas gestações únicas e múltiplas. Tendo em vista que a maioria das patologias maternas implicadas no aumento de risco de morte tem sua incidência aumentada em gestações gemelares, é de se esperar que gestações múltiplas predisponham a um maior risco de morte materna.

Conde Agudelo et al ${ }^{(85)}$, em um estudo realizado na América latina, concluem que mães com gestações gemelares tem um risco de morte duas vezes maior que aquelas portadoras de uma gestação única. Apenas um trabalho foi realizado em país desenvolvido sobre esse tema. Dessa forma, Senat et al ${ }^{(90)}$ observam taxa de morte materna em gestações gemelares de 10,2/100.000 nascidos vivos, enquanto que nas únicas é de 4,4/100.000 nascidos vivos.

\section{- Cesárea eletiva versus cesárea urgente}

Alguns trabalhos na literatura revelam que o risco de complicações é maior após uma cesárea urgente, quando comparado a um parto cesárea 
eletivo. Assim, Kamilya et al ${ }^{(38)}$ observam que o risco de morte é maior em pacientes portadoras de uma gestação única submetidas a um parto cesárea intraparto, quando comparado aquelas submetidas a um parto cesariana anteparto.

Leth et al ${ }^{(41)}$ publicam um artigo em que relatam maior risco de infecção de ferida cirúrgica naquelas pacientes submetidas a um parto cesárea urgente. Os autores observam aumento de risco de infecção de ferida cirúrgica de quase $50 \%$ nas pacientes submetidas a uma cesariana urgente quando comparadas àquelas submetidas a uma cesariana eletiva.

Skjeldestad e Oian ${ }^{(52)}$, num estudo caso-controle, procuram estudar a perda sanguínea após o parto cesárea, em gestações únicas e duplas. Os autores concluem que o risco de perda sanguínea grave é maior após um parto cesárea urgente (assim denominado, aquele ocorrido após um fórcipe falhado ou DPP) quando comparado a um parto cesárea eletivo. Gestações gemelares também apresentam maior chance de perda sanguínea do que as únicas.

Burrows et al ${ }^{(53)}$, em um estudo retrospectivo hospitalar com 32.834 pacientes com gestação única, observam que mulheres submetidas a uma primeira cesárea intraparto têm risco de endometrite aumentado em 21,3 vezes, quando comparadas com aquelas submetidas a um parto vaginal. Já as pacientes submetidas a uma primeira cesárea eletiva têm aumento de risco de 10,3 vezes quando comparadas com as submetidas a um parto vaginal. Entretanto, o risco de endometrite, após uma cesariana, é baixo, ao redor de $6,9 \%$. Pacientes submetidas a um parto vaginal têm maior chance de apresentarem hemorragia pós-parto do que aquelas submetidas a uma cesariana. Entretanto, a necessidade de transfusão de sangue é maior nas pacientes submetidas a um parto cesáreo intraparto do que nas submetidas a um parto vaginal. Pacientes submetidas a uma cesariana intraparto têm maiores riscos de trombose venosa profunda quando comparadas as pacientes que evoluíram com um parto vaginal.

Pallasmaa et al ${ }^{(54)}$, num estudo prospectivo multicêntrico, na Finlândia, comparam a taxa de complicações puerperais entre as pacientes 
submetidas a um parto cesariana eletivo (fora de trabalho de parto e com membranas íntegras), urgente (realizado em até 12 horas após sua indicação) e de emergência (realizado imediatamente após sua indicação). São estudadas 2.496 pacientes. A taxa de parto cesárea, no período estudado, é de 16,6\%. A taxa de cesárea eletiva é de $45,6 \%$, de cesárea urgente, de 46,5\% e de cesárea de emergência, de 7,9\%. Há maior risco de complicação após a cesárea de emergência do que na de urgência. O parto cesáreo eletivo apresenta as menores taxas de complicação. A presença de gestação múltipla aumenta o risco de complicações puerperais.

-Morbimortalidade puerperal em gestações gemelares de acordo com a via de parto

Poucos foram os estudos realizados em pacientes com gestação gemelar cujo objetivo tenha sido o de analisar exclusivamente a morbidade materna de acordo com a via de parto. Entretanto, existem alguns estudos com gestações gemelares que comparam os resultados neonatais, de acordo com a via de parto realizada ou planejada que incluíram dados de morbidade puerperal.

Em 1987, Rabinovic et al ${ }^{(56)}$ realizam um estudo randomizado, com 60 pacientes que apresentavam gestação gemelar, com a apresentação cefálica/não cefálica, para estudar as complicações maternas e fetais, de acordo com o parto normal planejado versus o parto cesáreo planejado. Eles observam que a morbidade febril puerperal está aumentada no grupo de parto cesáreo programado.

Em 2003, Hogle et al ${ }^{(28)}$ fazem uma metanálise da literatura para comparar os resultados maternos e neonatais do parto cesáreo planejado versus o parto vaginal programado em gestações gemelares com idades gestacionais $>32$ semanas ou peso fetal $>1500 \mathrm{~g}$. Dentre os quatro artigos selecionados, apenas um continha dados sobre morbidade materna 
(necessidade de transfusão de sangue). Os autores concluem que não há diferença entre as vias de parto quanto à morbidade materna.

Em 2005, Haest et al ${ }^{(59)}$ realizam um estudo retrospectivo de um único centro para avaliar os resultados maternos e fetais, de acordo com a via de parto planejado, em gestações gemelares com idade gestacional $\geq 32$ semanas. São analisadas 164 gestações. A morbidade materna grave estudada inclui a lesão genital, hemorragia materna, lesão intracirúrgica em bexiga, ureter ou trato gastrointestinal, sepsis, meningite, pneumonia, tromboembolismo, coagulação intravascular disseminada, insuficiência respiratória aguda, obstrução intestinal e embolismo amniótico. Os autores concluem não haver diferença significativa entre os grupos quanto à incidência de morbidade grave.

Schmitz et al ${ }^{(91)}$ realizam um estudo semelhante com 758 gestações com partos ocorridos acima de 35 semanas de gestação, em que o primeiro gemelar era cefálico. Também aqui é estudada a morbidade materna e neonatal de acordo com a via de parto. A morbidade materna estudada é a presença de hemorragia grave, admissão em UTI, complicação cardiopulmonar e morte. Não há diferença na incidência de complicações maternas entre os grupos de parto vaginal e parto cesariano planejado.

Sentilhes et al ${ }^{(55)}$ comparam a morbidade materna e perinatal entre o parto vaginal planejado e o parto cesáreo planejado em 195 gestações com o primeiro gemelar pélvico. A morbidade materna avaliada é: hemorragia puerperal > $500 \mathrm{ml}$, anemia, trombose venosa profunda ou embolia pulmonar, infecção e deiscência de ferida cirúrgica, febre e morte materna. Não há diferença significativa entre os grupos com relação à morbidade composta. Mas o grupo de parto cesáreo programado apresenta incidência significativamente maior de fenômenos tromboembólicos.

Algumas publicações analisam o custo relacionado às diferentes vias de parto. Em 1998, Mauldin et al ${ }^{(92)}$ analisam a influência da via de parto na relação custo-benefício no parto de gestações gemelares com apresentação cefálica/não cefálica. São analisadas as seguintes vias de parto: parto cesáreo, parto vaginal em que o segundo gemelar teve extração pélvica e o 
parto vaginal em que o segundo gemelar sofreu versão cefálica externa. Embora a morbidade materna seja igual entre os grupos, os custos maternofetais e o período de internação materna são menores, no grupo de parto normal, onde é realizada a extração pélvica. Luke et al ${ }^{(93)}$, ao analisar fatores que influenciam o custo da gestação gemelar, observam que os fatores responsáveis pela elevação de custos na gestação gemelar são o parto cesáreo, a pré-eclâmpsia e os partos prematuros.

Existem poucos estudos realizados em gestações gemelares que versam apenas sobre a morbidade materna, de acordo com a via de parto.

Alexander et al ${ }^{(57)}$ estudam 718 gestações para determinar se a maior manipulação intraparto relacionada ao nascimento do segundo gemelar está associada a um aumento do risco de infecção. Os tipos de parto estudados são: a cesárea, o parto vaginal sem manipulação (fetos na apresentação cefálica/cefálica) e o parto vaginal com manipulação (fetos na apresentação cefálica/não cefálica onde é realizada a extração pélvica para o nascimento do segundo gemelar). A taxa de endometrite é maior nas gestantes submetidas à cesárea quando comparadas com aquelas pacientes que evoluíram com um parto vaginal. Não há diferença na incidência de endometrite entre os 2 grupos de parto vaginal (onde a manipulação cirúrgica esteve ausente ou presente).

Num estudo retrospectivo, Simões et al ${ }^{(94)}$ comparam a morbidade puerperal em cesáreas eletivas com urgentes em gemelares. São comparadas 299 pacientes com gestações gemelares submetidas à cesárea eletiva com 80 gestantes com gestação gemelar que sofrem parto cesáreo de urgência (em vigência de trabalho de parto), versus 299 gestantes com gestações únicas que sofrem parto cesáreo eletivo. Os partos selecionados ocorrem em idade gestacional > 32 semanas e são excluídos os combinados. São analisados como morbidade materna: a febre puerperal, a infecção de cicatriz, a hemorragia pós-parto e o tromboembolismo venoso. Não há diferença entre os grupos com relação à incidência de febre puerperal, infecção de cicatriz e hemorragia puerperal. Trombose venosa ocorre em duas pacientes com gestação gemelar, sendo uma pós-cesárea 
eletiva e outra pós-cesárea de urgência. Os autores concluem não existir desvantagem no parto cesária programado em gestações gemelares.

Liu et al ${ }^{(95)}$, recentemente, num estudo retrospectivo de coorte, em um hospital japonês, procuram relacionar os fatores determinantes na escolha da via de parto e resultados maternos e fetais, de acordo com a via de parto realizada em gestações gemelares. São estudadas 197 gestações. A taxa de parto cesárea é de $82 \%$, sendo $47 \%$ cesáreas urgentes e $53 \%$, eletivas. Os resultados maternos estudados são a perda sanguínea, a transfusão de sangue e a necessidade de sutura compressiva ou de histerectomia para controle de hemorragia puerperal. A conclusão do estudo é que a via de parto (vaginal, cesárea eletiva ou cesárea urgente) não influencia os resultados maternos. 


\section{4 - MÉTODOS}

Este é um estudo retrospectivo dos partos de gestações gemelares ocorridos no Hospital das Clínicas da Faculdade de Medicina da Universidade de São Paulo entre 1993 e 2008.

Esta pesquisa foi aprovada pela Comissão de Ética para Análise de Projetos de Pesquisa (CAPPesq) do Hospital das Clínicas da Faculdade de Medicina da Universidade de São Paulo em 2008 (anexo A).

\subsection{CASUÍSTICA}

Critérios de inclusão

Foram definidos como critérios de inclusão:

- Pacientes com gestação gemelar (dois fetos) cujo parto tenha ocorrido no Hospital das Clínicas da Faculdade de Medicina da Universidade de São Paulo entre 1/1/1993 e 31/12/2008.

- A presença dos dois fetos vivos no momento da indicação da via de parto.

- Partos ocorridos após a $26{ }^{\text {a }}$ semana de gestação.

- As gestações cuja via de parto não tenha sido o combinado (o primeiro nasceu de parto vaginal e o segundo, de parto cesárea).

- As gestações onde os fetos não eram unidos.

- As gestações em que os desfechos maternos sejam conhecidos. 
Identificação e coleta de dados

Para a identificação dos casos, foram consultados os livros de registro de partos do Centro Obstétrico do HCFMUSP. A seguir, foram coletados os dados acerca de características demográficas e clínicas maternas, os dados referentes ao parto, os resultados maternos de morbidade e mortalidade, de acordo com a via de parto e os resultados de exames laboratoriais e anatomopatológicos realizados.

Os dados maternos clínicos foram obtidos por meio da pesquisa em seus respectivos prontuários hospitalares.

Os resultados de exames laboratoriais e anatomopatológicos foram checados no Sistema Informatizado de Informações Hospitalares (versão UNIX 1993) e no Sistema HCLAB, ambos do HCFMUSP.

\subsection{Variáveis do Estudo}

Aspectos clínicos e epidemiológicos maternos

Para cada gestante foram coletados dados clínicos e epidemiológicos assim identificados:

- Idade materna no momento do parto (em anos).

- Cor, definida como branca, parda ou negra.

- Paridade da paciente.

- A presença de parto cesáreo anterior.

- Antecedentes pessoais maternos, incluindo intercorrências clínicas, cirúrgicas e obstétricas prévias à gestação.

- Hábitos maternos (fumo ou uso de substâncias ilícitas).

- A corionicidade da gestação: determinada a partir do exame histopatológico da placenta realizada pela Patologia Clínica do HCFMUSP. $\mathrm{Na}$ falta deste, foi utilizado o laudo de ultrassonografia realizado no primeiro trimestre de gestação. Outros dados ainda utilizados foram a presença de 
discordância entre o sexo nos neonatos, assim como a presença de duas placentas após a dequitação, ambos indicativos de gestação dicoriônica. Assim, as gestações foram classificadas como dicoriônicas, monocoriônicas/ diamnióticas, monocoriônicas/monoamnióticas ou desconhecidas.

\subsection{Dados do parto}

Para todos os partos, os seguintes dados foram obtidos:

A- Idade gestacional do parto (expressa em semanas), determinada a partir da data da última menstruação, quando em conformidade com o primeiro exame de ultrassonografia realizado pela paciente. Em casos de discordância, a idade gestacional foi definida pela ultrassonografia mais precoce.

B- $O$ ano- calendário em que ocorreu o parto.

C- O motivo que levou à internação da paciente. Em caso de mais de uma internação, na gestação atual, foi considerada aquela na qual ocorreu o parto.

D- O motivo que levou à resolução da gestação.

E- $O$ fator determinante na escolha da via de parto.

F- O tipo de parto, definido como vaginal (VAG), cesárea eletiva (CesE) ou cesárea urgente (CesU).

O parto cesáreo eletivo foi definido como:

-Aquele realizado na ausência de trabalho de parto ou rotura prematura de membranas.

-Aquele que não apresentava fatores de urgência associados como: prolapso de cordão, sofrimento fetal, DPP, iminência de eclâmpsia, eclâmpsia, Hellp síndrome, edema agudo de pulmão, sepsis materna, acidente de punção na cordocentese, cirurgia realizada sob anestesia geral e sangramento da placenta prévia. 
G- O trabalho de parto no momento da indicação da via de parto, definido como a presença de contrações uterinas (pelo menos 2 em 10 minutos) associada a modificações cervicais progressivas.

$\mathrm{H}$ - A existência de gestação de alto risco no momento da indicação da via de parto, definida como:

- Doença hipertensiva grave, definida como a presença de préeclâmpsia grave(pressão arterial sistólica $\geq 140$ e/ou pressão arterial diastólica $\geq 90 \mathrm{mmHg}$, proteinúria $24 \mathrm{~h} \geq 5,0 \mathrm{~g} / \mathrm{L}$, oligúria, cianose e/ou edema pulmonar, iminência de eclampsia, eclâmpsia), doença hipertensiva da gestação superajuntada e hipertensão arterial complicada por insuficiência renal ou cardíaca.

- Placenta prévia.

- Descolamento prematuro de placenta.

- Cardiopatia materna.

- Edema agudo de pulmão.

- Anemia com necessidade de sangue.

-Trombofilias, trombose venosa profunda, tromboembolismo pulmonar e aquelas em uso de anticoagulação profilática, consideradas de alto risco tromboembólico.

- Plaquetopenia $<100.000 / \mathrm{mm}^{3}$.

- Insuficiência renal dialítica.

- Hepatopatia.

- Infecção grave como pancreatite, sepsis ou corioamnionite.

- Paciente HIV+/AIDS.

- Lúpus eritematoso sistêmico.

\subsection{Resultados maternos}

Os resultados maternos avaliados foram:

- Tempo de internação pós parto.

- Necessidade de reinternação e sua duração. 
- Ocorrência de complicações maternas após o parto, tais como:

- Hemorragia pós-parto com necessidade de transfusão de sangue ou tratamento com Ferro parenteral.

-Ocorrência de complicações infecciosas como:

Endometrite definida como pelo menos 2 picos febris, excetuando-se as primeiras 24 horas, associada à loquiação fétida e/ou útero amolecido, hipoinvoluído e doloroso sem a presença de outros focos infecciosos.

-Infecção de sítio cirúrgico com a necessidade de antibiótico parenteral.

-Infecção não cirúrgica como broncopneumonia (BCP) e colite pseudomembranosa.

- Necessidade de reabordagem cirúrgica.

-Transferência para UTI.

-Presença de lesão cirúrgica definida como laceração perineal de terceiro e quarto grau, prolongamento da incisão de histerotomia, lesão do trato urinário e/ou do trato gastrointestinal intraoperatório.

-Complicações clínicas graves como edema agudo de pulmão, insuficiência renal, derrame pleural e parada cardiorrespiratória revertida.

Histerectomia puerperal não programada.

- Fenômenos tromboembólicos.

- Morte.

\subsection{Armazenamento dos dados}

Todos os dados foram anotados nas fichas de coletas de dados (ANEXO B). A seguir as informações foram transferidas e armazenadas em uma planilha eletrônica EXCEL (Microsoft). 


\subsection{Análise estatística}

- Os resultados foram descritos segundo a média, desvio padrão e frequências absolutas e relativas. As comparações entre os grupos foram realizados pelos testes de Kruskal-Wallis e qui-quadrado. A análise de regressão múltipla anterógrada ("stepwise") foi utilizada para investigar os preditores significantes de complicação materna puerperal. A análise multivariada incluiu: idade materna, cor, presença de doença materna preexistente, paridade, presença de cesárea em gestação anterior, presença de gestação de alto risco, corionicidade, idade gestacional do parto, via de parto e a realização de cesariana intra-parto. O nível de significância estatístico foi definido como 0,05 , exceto para a análise multivariada em que foi definido como <0.2. A seguir, foi realizada a análise com a curva "Receiver Operating Characteristic" (ROC) para as variáveis contínuas e os riscos relativos e intervalo de confiança 95\% foram calculados para as variáveis absolutas que se mostraram significantes na regressão multivariada.

-Para a análise da incidência de complicação dos partos no período estudado, dividimos o período em 4 quadriênios (de 1993 a 1996, 1997 a 2000 , 2001 a 2004 e 2005 a 2008).

-Cálculo do tamanho amostral

De acordo com Simões et al, ${ }^{(94)}$, complicações maternas, após cesárea eletiva em gestações gemelares, são observadas em cerca de $8 \%$ dos casos. Para demonstrarmos um aumento de duas vezes na freqüência de complicações, segundo determinada característica preditora que esteja presente em cerca de $20 \%$ da população estudada, o tamanho amostral total necessário seria de 745 partos gemelares (para poder do cálculo de $80 \%$, e nível de significância de $5 \%$ ). 


\section{CARACTERIZACÃO DA AMOSTRA}

\subsection{Incidência}

No período estudado, foram identificados 880 partos gemelares, ocorridos com idade gestacional superior a 26 semanas, no HCFMUSP, em que ambos os fetos estavam vivos no momento da indicação da via de parto. Dentre estes, não foram recuperados prontuários em 42 casos $(4,7 \%)$. Sete pacientes $(0,8 \%)$ apresentavam um parto combinado e quatorze $(1,6 \%)$ apresentavam gêmeos unidos. A casuística do presente estudo incluiu, assim, 817 (92,8\%) partos para análise.

Houve 686 partos cesáreos ( 84,0\%) e 131 partos vaginais(16.0\%). Dentre as pacientes que tiveram cesarianas, $251(30,7 \%)$ foram eletivas e $435(53,2$ $\%)$, cesáreas urgentes.

\subsection{Aspectos clínicos e epidemiológicos maternos}

Idade materna

A idade materna variou na população estudada de 14 a 47 anos, com média de 28,5 $\pm 6,4$ anos (mediana de 28 anos). As pacientes que evoluíram para o parto cesárea eletivo apresentavam uma média de idade maior quando comparadas às que tiveram parto cesárea urgente (CesE: 29,3 $\pm 6,4$ versus CesU: $28.0 \pm 6.3 ; p=0,03$ ) 
COR

Na população geral estudada, $426(52,1 \%)$ pacientes apresentavam a cor branca, $283(34,6 \%)$ eram pardas e $108(13,2 \%)$ negras. Nas pacientes submetidas a uma cesariana eletiva, a proporção da cor branca foi menor quando comparadas com as pacientes que evoluíram com um parto vaginal ou uma cesariana urgente (CesE: $45,8 \%$ versus VAG: $57,3 \%$ versus CesU: $54,3 \% ; p=0,05)$.

\section{Paridade}

Na população estudada, a paridade variou de 0 a 17, com média de $1,3 \pm 1,6$ (mediana de 1).

\section{Parto cesáreo anterior}

Na população estudada, 215 pacientes $(26,3 \%)$ apresentavam um parto cesáreo anterior, com um máximo de até 5 cesáreas anteriores, sendo a média de cesáreas anteriores $0,4 \pm 0,8$ (mediana 0 ). As pacientes que evoluíram com um parto vaginal apresentavam uma incidência de cesariana em gestações anteriores significativamente menor que aquelas que evoluíram para uma cesariana eletiva ou urgente $(\mathrm{VAG}=5,3 \%$ versus $\mathrm{CesE}=$ $33,5 \%$ versus $\mathrm{CesU}=28,5 \% ; p<0.001$ ).

Antecedentes pessoais

Dentre todas as pacientes, 232 apresentavam alguma patologia prévia como antecedente pessoal $(28,4 \%)$. 
Hábitos

$\mathrm{Na}$ população estudada, apenas $58(7,1 \%)$ pacientes referiam 0 hábito de fumar ou de usar substâncias ilícitas.

\section{Corionicidade}

A análise da população estudada permitiu observar que $549(67,2 \%)$ eram dicoriônicas, 196 (24,0\%), monocoriônicas diamnióticas, 23 (2,8\%), monocoriônicas monoamnióticas e 49 (6,0\%) tinham corionicidade ignorada.

A tabela 1 resume os aspectos clínicos e epidemiológicos maternos. 
TABELA 1 - Características maternas e dados gestacionais em 817 pacientes com gestações gemelares de acordo com a via de parto, (HCFMUSP- 19932008)

\begin{tabular}{|c|c|c|c|c|c|}
\hline & Total & Vaginal & $\begin{array}{l}\text { Cesárea } \\
\text { eletiva }\end{array}$ & $\begin{array}{l}\text { Cesárea } \\
\text { urgente }\end{array}$ & $p+$ \\
\hline$n$ & 817 & 131 & 252 & 434 & \\
\hline idade materna, anos & $28.5 \pm 6.4$ & $28.4 \pm 6.9$ & $29.3 \pm 6.4$ & $28.0 \pm 6.3$ & $\begin{array}{c}0.03 \\
\text { CesE versus } \\
\text { CesU: } p=0.01\end{array}$ \\
\hline branco (\%) & $426(52.1)$ & 75 (57.3) & $115(45.8)$ & $236(54.3)$ & 0.05 \\
\hline \multirow[t]{2}{*}{ Nulipara(\%) } & $314(38.4)$ & $46(35.1)$ & $96(38.2)$ & $172(39.5)$ & 0.66 \\
\hline & & & & & $<0.001$ \\
\hline \multirow[t]{2}{*}{ Cesárea prévia (\%) } & $215(26.3)$ & $7(5.3)$ & $84(33.5)$ & $124(28.5)$ & $\begin{array}{l}\text { VAG versus CesE: } \\
\qquad p<0.001\end{array}$ \\
\hline & & & & & $\begin{array}{c}\text { VAG versus CesU: } \\
p<0.001\end{array}$ \\
\hline $\begin{array}{l}\text { Gestação dicoriônica } \\
(\%)\end{array}$ & $549(67.2)$ & $81(61.8)$ & $173(68.9)$ & $295(67.8)$ & 0.35 \\
\hline Doença materna (\%) & $232(28.4)$ & $33(25.2)$ & $77(30.7)$ & $122(28.0)$ & 0.51 \\
\hline \multirow[t]{2}{*}{$\begin{array}{l}\text { Gestação de alto risco } \\
(\%)^{*}\end{array}$} & $143(17.5)$ & $13(9.9)$ & $47(18.7)$ & $83(19.1)$ & 0,05 \\
\hline & & & & & $<0.001$ \\
\hline \multirow[t]{2}{*}{$\begin{array}{l}\text { Tempo de internação } \\
\text { puerperal, dias }\end{array}$} & $3.1 \pm 2.5$ & $2.7 \pm 1.6$ & $2.9 \pm 1.7$ & $3.4 \pm 3.1$ & $\begin{array}{c}\text { CesU versus VAG: } \\
\qquad p=0.001\end{array}$ \\
\hline & & & & & $\begin{array}{l}\text { CesU versus } \\
\text { CesE: } p<0.001\end{array}$ \\
\hline \multirow[t]{2}{*}{$\begin{array}{l}\text { Reinternação } \\
\text { hospitalar (\%) }\end{array}$} & $11(1.3)$ & $1(0.8)$ & $1(0.4)$ & $9(2.1)$ & 0.15 \\
\hline & & & & & $<0.001$ \\
\hline \multirow[t]{2}{*}{$\begin{array}{l}\text { Idade gestacional do } \\
\text { parto, semanas }\end{array}$} & $35.6 \pm 2.8$ & $35.1 \pm 3.3$ & $36.7 \pm 2.3$ & $35.1 \pm 2.8$ & $\begin{array}{c}\text { CesE versus VAG: } \\
p<0.001\end{array}$ \\
\hline & & & & & $\begin{array}{c}\text { CesE versus } \\
\text { CesU: } p<0.001\end{array}$ \\
\hline $\begin{array}{l}\text { Peso de nascimento, } \\
\text { gramas }\end{array}$ & $2214 \pm 593$ & $2154 \pm 571$ & $2359 \pm 567$ & $2148 \pm 600$ & $<0.001$ \\
\hline $1^{\circ}$ gemelar & $2239 \pm 579$ & $2172 \pm 563$ & $2397 \pm 549$ & $2168 \pm 585$ & $\begin{array}{c}\text { CesE versus VAG: } \\
p<0.001\end{array}$ \\
\hline $2^{\circ}$ gemelar & $2188 \pm 605$ & $2136 \pm 580$ & $2320 \pm 583$ & $2127 \pm 614$ & $\begin{array}{l}\text { CesE versus } \\
\text { CesU: } p<0.001\end{array}$ \\
\hline
\end{tabular}

Os resultados estão apresentados como média \pm desvio padrão ou como frequências absolutas e relativas.

+ : Testes de Mann Whitney e Qui quadrado

* Gestações complicadas por anemia com necessidade de transfusão de sangue, trombocitopenia, cardiopatia, edema agudo de pulmão, hepatopatia, pancreatite, sepsis, corioamnionite, insuficiência renal, pacientes com alto risco tromboembólico, doença ipertensiva grave, placenta prévia, descolamento prematuro de placenta, HIV+, Lupus eritematoso sistêmico. 


\subsection{Dados do parto}

Idade gestacional do parto

A idade gestacional variou, na população estudada, de $261 / 7$ a 42 2/7 semanas, com média de 35 4/7 \pm 2 6/7 semanas (mediana de 36 2/7 semanas). As pacientes que evoluíram com parto cesárea eletiva apresentaram uma idade gestacional de nascimento significativamente maior quando comparada com as pacientes que tiveram um parto vaginal ou um parto cesárea urgente $(\mathrm{CesE}=36,7 \pm 2,3$ versus $\mathrm{VAG}=35,1 \pm 3,3$ versus CesU= $35.1 \pm 2.8, p<0,001)$.

Motivo da internação da paciente

Os principais motivos que levaram à internação da paciente na enfermaria da Clínica Obstétrica do HCFMUSP estão sumarizados na tabela 2: 
Tabela 2 - Motivo da internação de 817 pacientes com gestação gemelar na Clínica Obstétrica do HCFMUSP entre 1993 a 2008.

\begin{tabular}{ccc}
\hline Motivo da internação & $\mathrm{n}$ & $\%$ \\
\hline Trabalho de parto prematuro & 224 & 27,4 \\
Doenças hipertensivas & 112 & 13,7 \\
Resolução/termo & 101 & 12,4 \\
Controle de vitalidade/RCUl/oligoâmnio & 85 & 10,4 \\
Trabalho de parto & 75 & 9,2 \\
Descompensação clínica materna & 74 & 9,1 \\
RPMO & 71 & 8,7 \\
Gemelar para repouso & 43 & 5,2 \\
outros & 54 & 6,6 \\
\hline Total & 817 & 100 \\
\hline
\end{tabular}

RCUI: restrição de crescimento intraútero; RPMO: rotura prematura de membranas. 
Motivo da resolução da gestação

Os diferentes motivos que indicaram a interrupção da gestação estão listados na tabela 3.

TABELA 3 - Motivo da resolução da gestação em 817 pacientes com gestação gemelar na Clínica Obstétrica do HCFMUSP entre 1993 a 2008.

\begin{tabular}{lcc}
\hline Indicação & $\mathbf{n}$ & \% \\
\hline Trabalho de parto & 446 & 54,6 \\
Termo/maturidade & 165 & 20,2 \\
Alteração de vitalidade/sofrimento fetal/CIUR & 99 & 12,1 \\
Doença hipertensiva/Patologia materna grave & 42 & 5,1 \\
RPMO+ e IG>36 semanas/infecção ovular & 37 & 4,5 \\
Alteração do volume de LA & 15 & 1,9 \\
DPP/PP & 9 & 1,1 \\
Outros & 4 & 0,5 \\
\hline Total & 817 & 100 \\
\hline
\end{tabular}

CIUR: restrição de crescimento intraútero; RPMO: rotura prematura de membranas; IG: idade gestacional; LA: líquido amniótico; DPP: descolamento prematuro de placenta; PP: placenta prévia.

Indicação da cesariana

A tabela 4 indica os diferentes motivos que levaram à indicação do parto cesáreo. 
Tabela 4 - Indicação da cesariana realizada no HCFMUSP em 686 pacientes com gestação gemelar no período de 1993 a 2008.

\begin{tabular}{lcc}
\hline Motivo & $\mathrm{n}$ & $\%$ \\
\hline G1 não cefálico & 172 & 25,1 \\
Contra indicação p/ indução & 126 & 18,4 \\
Cirurgia uterina prévia & 95 & 13,8 \\
Alteração vitalidade/ Sofrimento fetal & 83 & 12,1 \\
Prematuridade & 40 & 5,8 \\
G2 não cefálico & 33 & 4,8 \\
Doença materna grave & 27 & 3,9 \\
Distocia funcional & 23 & 3,4 \\
G2>G1 em mais que 500 g & 15 & 2,2 \\
Malformação fetal & 14 & 2,0 \\
PP/DPP & 11 & 1,6 \\
Outros & 47 & 6,9 \\
\hline Total & 686 & 100 \\
\hline
\end{tabular}

G1: primeiro gemelar; G2: segundo gemelar; PP: placenta prévia; DPP: descolamento prematuro de placenta.

Presença de trabalho de parto no momento da indicação da via de parto

O trabalho de parto estava presente no momento da indicação da via de parto em 454 pacientes (55,6\%). Dentre as 686 pacientes que evoluíram com o parto cesárea, $323(47,1 \%)$ estavam em trabalho de parto no momento da indicação da via de parto.

Gestação de alto risco

Das 817 pacientes, $143(17,5 \%)$ apresentavam, no momento da decisão da via de parto, uma doença grave complicando a gestação. Aquelas, cujo parto foi vaginal tiveram incidência significativamente menor 
de gestação de alto risco, em relação as que evoluíram para a cesárea eletiva e cesárea urgente (VAG: 9,9\% versus CesE: 18,7\% versus CesU: $19,1 \%, p=0,05)$.

A tabela 5 sumariza as patologias graves apresentadas pelas pacientes desta casuística.

TABELA 5 - Frequência de doença materna grave nas pacientes com gestação de alto risco no momento da indicação da via de parto em 143 pacientes submetidas a parto no HCFMUSP entre 1993 e 2008.

\begin{tabular}{lcc}
\hline Doença & $\mathbf{n}$ & $\%$ \\
\hline Doença hipertensiva grave & 72 & 50,3 \\
Cardiopatia materna. & 26 & 18,2 \\
Risco tromboembólico & 8 & 5,6 \\
PP & 6 & 4,2 \\
Paciente HIV+/AIDS. & 6 & 4,2 \\
Infecção grave & 6 & 4,2 \\
DPP & 4 & 2,8 \\
Anemia com necessidade de sangue. & 4 & 2,8 \\
Lupus eritematoso sistêmico . & 4 & 2,8 \\
Plaquetopenia & 3 & 2,1 \\
Hepatopatia. & 2 & 1,4 \\
Insuficiência renal dialítica. & 1 & 0,7 \\
Edema Agudo de pulmao & 1 & 0,7 \\
\hline total & 143 & 100 \\
\hline
\end{tabular}

PP: placenta prévia; DPP: descolamento prematuro de placenta; HIV+/AIDS: portadora do vírus HIV ou da síndrome de imunodeficiência humana adquirida. 


\section{$\underline{6-\text { RESULTADOS }}$}

\section{1 - Tempo de internação pós-parto}

O tempo médio de internação pós-parto das pacientes internadas na clínica obstétrica do HCFMUSP foi de 3,1 2 2.5 dias.

As pacientes submetidas à cesárea urgente ficaram mais tempo internadas do que as que se sujeitaram a parto vaginal ou à cesariana eletiva $(\mathrm{CesU}=3.4 \pm 3.1$ versus $\mathrm{VAG}=2.7 \pm 1.6$ versus $\mathrm{CesE}=2.9 \pm 1.7 ; p<$ 0.001).

\section{2 - Readmissão hospitalar}

Apenas $11(1,3 \%)$ pacientes precisaram ser reinternadas, sendo que uma delas havia sido submetida ao parto vaginal $(0,8 \%)$, outra à cesariana eletiva $(0,4 \%)$ e nove à cesariana urgente $(2,1 \%)$. A primeira delas permaneceu 9 dias internada, a segunda, apenas 1 dia e as demais, em média 8,4 \pm 6,4 dias (mediana de 7 dias).

\section{3 - Taxa de complicação materna pós-parto}

Das 817 pacientes analisadas, 56 apresentaram pelo menos uma complicação pós-parto (6,9\%). Algumas pacientes apresentaram mais de uma. Assim, estas 56 pacientes tiveram 90 complicações diferentes. As complicações puerperais foram observadas em 5,3\% das pacientes submetidas a parto vaginal, $4,0 \%$ à cesariana eletiva e $9,0 \%$ à cesariana urgente $(p=0,03)$. As pacientes submetidas à cesárea urgente tiveram taxa 
de complicação puerperal significativamente maior que aquelas sujeitas à cesariana eletiva (Ces $E$ versus cesU: $p=0,02$ ).

\section{4 - Taxa de complicações maternas estratificadas}

A análise estratificada das diferentes complicações maternas revelou que as pacientes submetidas à cesárea urgente apresentaram maior incidência de complicações infecciosas do que as que tiveram cesariana eletiva (CesU $=3,7 \%$ versus CesE $=0,8 \% ; p=0,04)$.

A incidência de hemorragia pós-parto, histerectomia puerperal, reoperação, lesão cirúrgica, complicações clínicas graves, fenômenos tromboembólicos, transferência para UTI e morte foi idêntica entre os grupos.

A tabela 6 sumariza as complicações puerperais nas diferentes vias de parto. 
Tabela 6. Complicações puerperais em partos de gestações gemelares ocorridas no HCFMUSP de acordo com a via de parto realizada no período de 1993 a 2008.

\begin{tabular}{|c|c|c|c|c|c|}
\hline & $\begin{array}{l}\text { Total } \\
(n=817)\end{array}$ & $\begin{array}{c}\text { Parto } \\
\text { Vaginal } \\
(n=131)\end{array}$ & $\begin{array}{c}\text { Cesárea } \\
\text { eletiva } \\
(n=252)\end{array}$ & $\begin{array}{l}\text { Cesárea } \\
\text { urgente } \\
(n=434)\end{array}$ & $p^{*}$ \\
\hline $\begin{array}{l}\text { Pelo menos uma } \\
\text { complicação }\end{array}$ & $56(6.9)$ & $7(5.3)$ & $10(4.0)$ & $39(9.0)$ & $\begin{array}{c}0.03 \\
\text { CesE versus } \\
\text { CesU: } p=0.02\end{array}$ \\
\hline $\begin{array}{l}\text { Hemorragia com } \\
\text { necessidade de } \\
\text { transfusão }\end{array}$ & $24(2.9)$ & $2(1.5)$ & $6(2.4)$ & $16(3.7)$ & 0.37 \\
\hline $\begin{array}{l}\text { Complicação } \\
\text { infecciosa đI }\end{array}$ & $20(2.4)$ & $2(1.5)$ & $2(0.8)$ & $16(3.7)$ & $\begin{array}{c}0.048 \\
\text { CesE versus } \\
\text { CesU: } p=0.04\end{array}$ \\
\hline Endometrite & $11(1.3)$ & - & $2(0.8)$ & $9(2.1)$ & 0.13 \\
\hline $\begin{array}{l}\text { Infecção do sítio } \\
\text { cirúrgico }\end{array}$ & $8(1.0)$ & $1(0.8)$ & - & $7(1.6)$ & 0.12 \\
\hline $\begin{array}{l}\text { Infecção não } \\
\text { cirúrgica }\end{array}$ & $4(0.5)$ & $1(0.8)$ & - & $3(0.7)$ & 0.41 \\
\hline $\begin{array}{l}\text { Necessidade de } \\
\text { reabordagem } \\
\text { cirúrgica }\end{array}$ & $13(1.6)$ & $2(1.5)$ & $1(0.4)$ & $10(2.3)$ & 0.16 \\
\hline Admissão em UTI & $9(1.1)$ & - & $3(1.2)$ & $6(1.4)$ & 0.41 \\
\hline Lesão cirúrgica & $6(0.7)$ & $2(1.5)$ & $1(0.4)$ & $3(0.7)$ & 0.47 \\
\hline $\begin{array}{l}\text { Complicação } \\
\text { clínica grave } ¥\end{array}$ & $6(0.7)$ & - & - & $6(1.4)$ & 0.07 \\
\hline HTA & $4(0.5)$ & - & $1(0.4)$ & $3(0.7)$ & 0.59 \\
\hline $\begin{array}{l}\text { Fenômenos } \\
\text { tromboembólicos }\end{array}$ & $4(0.5)$ & - & - & $4(0.9)$ & 0.17 \\
\hline Morte materna & $1(0.1)$ & - & - & $1(0.2)$ & 0.64 \\
\hline
\end{tabular}

Os valores entre parênteses representam porcentagens; * Teste de Qui quadrado.

UTI: Unidade de terapia intensiva; HTA: Histerectomia total abdominal

I: definido como broncopneumonia e colite pseudomembranosa.

¥: definido como edema agudo de pulmão, insuficiência renal, derrame pleuram e parada cardiorespiratória revertida 


\section{5 - Análise multivariada}

Procedeu-se à análise de regressão múltipla para a presença de complicação materna com os seguintes preditores: idade materna, cor, doença materna preexistente, paridade, cesárea em gestação anterior, gestação de alto risco, corionicidade, idade gestacional do parto, via de parto e a realização de cesariana intraparto.

A análise multivariada revelou que apenas as comorbidades graves, a cesárea urgente e a idade gestacional do parto estiveram implicadas em um aumento significativo na incidência de complicações puerperais maternas.

Os dados da análise multivariada estão resumidos na tabela 7.

TABELA 7: Níveis de significância para as variáveis independentes na análise da predição de qualquer complicação materna nos partos de gestações gemelares ocorridas no HCFMUSP entre 1993 a 2008

\begin{tabular}{lc}
\hline Variáveis independentes & $\mathbf{P}$ \\
\hline Corionicidade & 0,193 \\
Hábitos mãe & 0,187 \\
gestação de alto risco & $<0,001$ \\
Via de parto & 0,085 \\
Cor & 0,450 \\
Idade & 0,520 \\
Cesárea anterior & 0,526 \\
Cesárea em Trabalho de parto & 0,382 \\
Antecedentes pessoais & 0,192 \\
Idade gestacional parto & 0,007 \\
Paridade & 0,320 \\
\hline
\end{tabular}

A análise multivariada anterógrada revelou que as variáveis significativas foram a gestação de alto risco $(p<0,0001)$, seguida de idade gestacional do parto $(p=0,011)$ e, finalmente, a via de parto $(p=0,127)$. A melhor fórmula foi descrita como $0.286+(0.018$ * via de parto) - (0.008 * idade gestacional do parto $)+\left(0.104^{*}\right.$ gestação de alto risco $)(r=0.20)$. A 
seguir, foi realizada uma análise separada de cada uma das variáveis que se mostraram relevantes no modelo multivariado.

A análise da influência da presença de gestação de alto risco nos resultados maternos revelou que o grupo que apresentava gestação com maiores comorbidades teve taxa de complicação significativamente maior. Assim, 143 pacientes (17.5\%) foram alocadas no grupo que apresentavam um maior risco obstétrico e 674 pacientes (82.5\%) foram alocadas no grupo de menor risco obstétrico. As pacientes que apresentavam gestação de alto risco apresentaram uma taxa de complicação de 16,1\% contra 4,9 \% no grupo de menor risco $(p<0,01)$. A presença de gestação de alto risco conferiu um risco relativo de complicações puerperais de 3,29 (IC95\% 1,99$5,36)$.

Foi realizada também análise da influência da idade gestacional do parto na incidência de complicações maternas puerperais. A predição do desfecho da morbidade materna, segundo a idade gestacional, por meio da área sob a curva ROC foi de 0,61 (IC95\% 0,51-0,71). ( Figura 1 ) 
Figura 1: Curva ROC "Receiver Operating Characteristic" para a idade gestacional de nascimento na predição de complicações materna puerperais em gestação gemelar. Área sob a curva =0,61 (IC95\% 0,51 a 0,71)

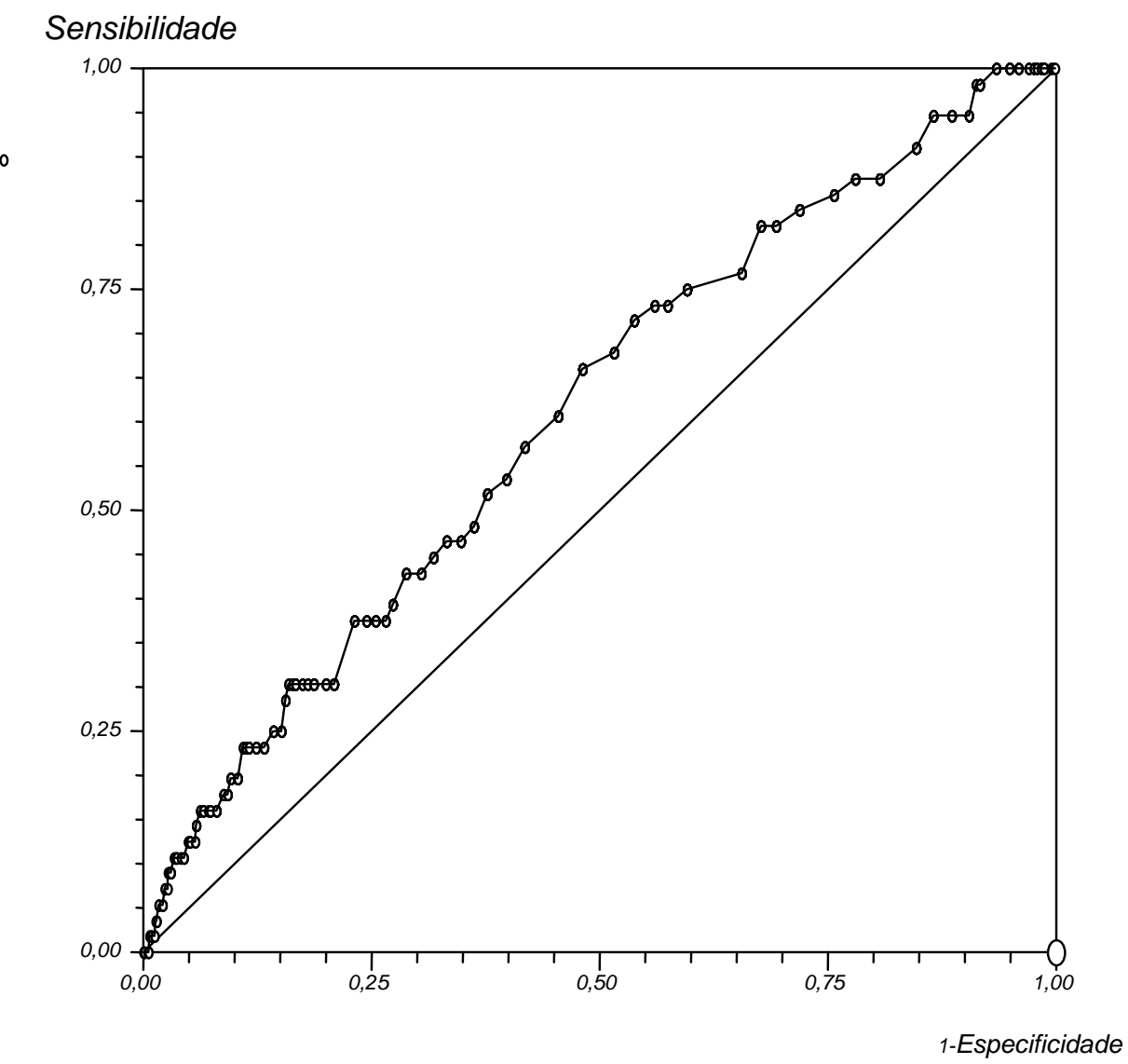

A análise de risco relativo relativo revelou que foram significativos os partos realizados abaixo de 33sem, com risco relativo(RR) de 1,82 (IC95\%: 1,06-3,08) e abaixo de 32sem, RR 1,86 (IC 1,03-3,29).

A análise da influência da via de parto na predição de complicações maternas mostra que a cesariana urgente tem risco relativo de 2,34 (IC95\%: $1,21-4,57)$ de complicações em relação à cesariana eletiva. Não se observou aumento de risco na comparação do parto vaginal com a cesárea eletiva ou o parto vaginal com a cesariana urgente. 


\section{6 - Evolução temporal das complicações puerperais}

Ao se analisar a incidência de partos de gestações gemelares ocorridos no HCFMUSP entre 1993 a 2008, foi observada tendência significativa do aumento nas taxas de parto cesáreo, saindo de $66,7 \%$, no primeiro quadriênio, chegando a $92,6 \%$ no último quadriênio $(p<0,001)$. Entretanto, as taxas de complicação do parto cesáreo permaneceram estáveis no período, em torno de $7 \%$. Também foi evidenciado aumento significativo nas incidências de cesarianas eletivas no período, indo de $21,6 \%$ dos partos no primeiro quadriênio para $47,2 \%$ dos partos no último quadriênio ( $p<0,0001)$. Isso foi acompanhado de menor incidência de partos vaginais e cesarianas urgentes no período estudado (incidência de parto vaginal em $1993-1996=33,3 \%$ de partos e em $2005-2008=7,4 \%$ de partos, $p<0,0001$; incidência de cesariana urgente, $1993-1996=74,4 \%$ dos partos e em $2005-2008=52,8 \%$ dos partos, $p<0,0001)$. As taxas de complicação pósparto não apresentaram variação no período. A tabela 8 sumariza a evolução temporal das complicações maternas nas diferentes vias de parto.

Tabela 8. Evolução temporal das complicações puerperais em gestações gemelares, no HCFMUSP, de acordo com a via de parto, no período de 1993 a 2008

\begin{tabular}{cccccc}
\hline Via de parto & $\mathbf{1 9 9 3 - 1 9 9 6}$ & $\mathbf{1 9 9 7 - 2 0 0 0}$ & $\mathbf{2 0 0 1 - 2 0 0 4}$ & $\mathbf{2 0 0 5 - 2 0 0 8}$ & $\mathbf{p}^{*}$ \\
\hline VAG & $3 / 41(7,3)$ & $2 / 34(5,9)$ & $1 / 36(2,8)$ & $1 / 20(5,0)$ & 0,9 \\
CesE & $1 / 21(4,8)$ & $0 / 31(-)$ & $3 / 81(3,7)$ & $6 / 118(5,1)$ & 0,67 \\
CesU & $6 / 61(9,8)$ & $13 / 114(11,4)$ & $8 / 128(6,3)$ & $12 / 132(9,1)$ & 0,54 \\
\hline
\end{tabular}

VAG: parto vaginal; CesE: cesárea eletiva; CesU: cesárea urgente; *: Qui quadrado ou Fisher Valores entre parênteses representam valores relativos. 


\section{7 - DISCUSSÃO}

O Brasil é reconhecido como um país com altas taxas de parto cesáreo. Em 2010, foi de 52,3\%, sendo esta taxa de 78,7\% em gestações gemelares ${ }^{(5)}$.

O Hospital das Clínicas da FMUSP é um hospital terciário, sendo referência para pacientes que requerem um atendimento de alta complexidade. Assim, casos de pré-natal de alto risco são referenciados para esse serviço. Para isso, há um ambulatório especializado em gestação múltipla.

Há grande controvérsia na literatura sobre a melhor via de parto para gestações gemelares. Poucos estudos foram realizados para avaliar a influência da via de parto nos resultados maternos em gestações múltiplas. A maioria dos estudos que fazem menção a complicações puerperais maternas foi realizada para comparar os resultados neonatais, de acordo com a via de parto. Outros estudos visam comparar a morbidade puerperal nas diferentes vias de parto e acabam por comparar gestações únicas com múltiplas. Sabe-se que gestações gemelares apresentam maiores riscos do que as únicas. Assim, o ideal para se estudar a morbidade puerperal materna em gestações gemelares seria incluir apenas gestações gemelares.

\section{1 - Caracterização da amostra}

Dados clínicos e epidemiológicos maternos

A caracterização da amostra revela algumas diferenças nos aspectos clínicos e epidemiológicos maternos, entre as pacientes, de acordo com as vias de parto. 
As pacientes que evoluíram para cesárea eletiva tinham maior média de idade. A idade gestacional de nascimento e o peso de nascimento dos recém-nascidos também foram maiores nesta via de parto. Um trabalho realizado por Pallasmaa et al ${ }^{(54)}$, em que são estudadas as complicações maternas em cesarianas, também constata que pacientes submetidas à cesariana eletiva eram mais velhas.

Sabe-se que a prematuridade é um grande problema em gestações gemelares. A média de idade gestacional de nascimento desta pesquisa está em conformidade com Alexander ${ }^{(10)}$ que observou que, nos Estados Unidos, entre 95 a 98 , ela foi de 35,6 semanas. Pallasmaa et al ${ }^{(54)}$, estudando os partos cesáreos, na Finlândia, também observa que os partos cesáreos urgentes tendem a ocorrer em idades gestacionais menores. Neste estudo prospectivo multicêntrico, 2.496 pacientes com gestações únicas e gemelares foram analisadas.

Por outro lado, estudo realizado por Simões et al ${ }^{(60)}$, que comparou o parto cesáreo eletivo com cesárea urgente, em 379 gestações gemelares, não observa diferença na idade gestacional de nascimento. A idade gestacional média de nascimento foi de 35,9 \pm 1,4 semanas na cesárea eletiva e 35,8 \pm 1,6 semanas na cesárea urgente. Nossa casuística apresentou maior idade gestacional de nascimento na cesárea eletiva. Simões não explica, em sua publicação, o critério de determinação da idade gestacional de nascimento nas cesáreas eletivas. Na Clínica obstétrica do HCFMUSP, desde 2002, gestações dicoriônicas são resolvidas com 38 semanas; aquelas com massa placentária única diamnióticas, com 37 semanas; as monocoriônicas diamnióticas, com 36 semanas, e as monocoriônicas e monoamnióticas, com 34 semanas. Assim, a corionicidade é determinante do momento da resolução da gestação.

Há muita controvérsia na literatura sobre a idade gestacional ótima de nascimento dos gemelares. Diversas publicações na literatura evidenciam que gestações gemelares apresentam o nadir de mortalidade ao redor de 37-38 semanas ${ }^{(96,97)}$. Sabe-se que gestações monocoriônicas apresentam um pior prognóstico perinatal, principalmente relacionado com a Síndrome 
de transfusão feto-fetal e maior risco de óbito intrauterino ${ }^{(98)}$. Estudo retrospectivo conduzido por Lee et al ${ }^{(98)}$, observa que o nadir de óbito intraútero em gestações monocoriônicas/ diamnióticas seria com 34 semanas. Assim, os autores sugerem que a resolução dessas gestações seja por volta de 34-35 semanas, após a corticoterapia. Simões et al ${ }^{(99)}$ analisam o assunto e concluem que a idade gestacional ótima para o nascimento nessas gestações seria por volta de 36 semanas. Smith et al ${ }^{(100)}$ também concorda que elas deveriam ser prolongadas até 36-37 semanas.

Nossa casuística revelou que os recém-nascidos de gestantes submetidas a uma cesariana eletiva apresentavam maior média de peso. Isto pode ser atribuído à idade maior de nascimento. Liu et al ${ }^{(95)}$, estudando a influência da via de parto nos resultados de partos de gestações gemelares, também observa maior peso de nascimento nos gemelares de mães submetidas a uma cesárea eletiva.

Outra diferença constatada na epidemiologia desta casuística foi a de que as pacientes que evoluíram para o parto vaginal apresentavam menor incidência de cesárea em gestação anterior e de gestação de alto risco no pré-natal em questão, em conformidade com a literatura médica. Para muitos obstetras e também na Clínica Obstétrica do HCFMUSP, a ocorrência de cesárea em gestação anterior em uma paciente com gestação múltipla contraindica o parto vaginal ${ }^{(72)}$. A menor incidência de gestação de alto risco nas pacientes submetidas a parto vaginal pode ser explicado pelo fato de que as gestações com maiores complicações, geralmente, apresentam patologias que acabam sendo indicações para a cesariana.

\section{2. - Dados do parto}

As principais razões para a internação de pacientes na enfermaria da Clínica Obstétrica foram o trabalho de parto prematuro, as doenças hipertensivas e a resolução da gestação pelo atingimento do termo. 
A literatura médica aponta a prematuridade como a principal complicação da gestação múltipla. Alexander e Salihu ${ }^{(10)}$, num estudo da população americana, registram $52,3 \%$ de parto pré- termo em gestação gemelar. Blondel et al ${ }^{(9)}$, em uma análise da relação parto pré-termo com gestações gemelares, na Europa, observa que a incidência de prematuridade variou de $42,2 \%$ a $68,4 \%$ nos países estudados.

A literatura médica também aponta que doenças hipertensivas são mais comuns nessas gestações ${ }^{(10,11)}$.

A análise dos principais motivos que levaram à resolução da gestação, nesta casuística, mostra que o trabalho de parto foi a principal indicação, seguido do termo/maturidade da gestação e da alteração de vitalidade fetal. Assim, no momento da resolução da gestação, $54,6 \%$ das pacientes se encontravam em trabalho de parto. Assunção et al ${ }^{(101)}$, em uma publicação anterior, cujo estudo também foi realizado no HCFMUSP, em gestações gemelares, observou, em 49,8\%, o início espontâneo do trabalho de parto como razão da indicação do parto.

As principais causas da indicação de cesárea foram: apresentação não cefálica do primeiro gemelar, contra indicação para a indução, a ocorrência de cirurgia uterina prévia e a alteração da vitalidade ou sofrimento fetal.

Liu et al ${ }^{(95)}$, recentemente, publicou um artigo para determinar os fatores que influenciam a escolha da via de parto em gestações gemelares. Foi realizado em um hospital japonês com taxa de cesárea para gestação múltipla de $82 \%$. Ele encontrou como principais indicações da via de parto: a cesárea a pedido materno, a má-apresentação fetal, a restrição de crescimento intrauterina e a hipertensão gestacional. O serviço do HCFMUSP não realiza a cesárea a pedido materno. Assim, nosso resultado de que a má apresentação fetal é um importante fator determinante de parto cesárea é compatível com o obtido por Liu et al .

Na Clínica Obstétrica do HCFMUSP, no período estudado, a indução do parto em gestações mútiplas não era realizada. Desta forma, as 
pacientes que tinham indicação para a resolução, mas que estavam fora de trabalho de parto, foram submetidas à cesárea.

O fato de a cicatriz uterina prévia ter sido a terceira causa mais comum de indicação do parto reflete os altos índices de cesáreas no Brasil, que, em 2010 foi de $52,3 \%$. Portanto, sendo o Brasil um país com altíssimas taxas de cesárea, é importante observar que a cesárea em gestação anterior aumenta o risco de novas cesarianas em gestações futuras, principalmente em gestações gemelares. Assim, isto é um dos fatores que contribuiu para nossas altas taxas de parto cesariana em gestações gemelares, que se encontram acima do descrito na literatura médica. Lee et al ${ }^{(36)}$ descrevem taxa de cesariana em gestações gemelares de $75,0 \%$ nos Estados Unidos em 2008. Em 2008, no HCFMUSP a taxa de cesariana foi de $94,3 \%$ das pacientes.

Foi observado, nesta casuística, que $17,5 \%$ das pacientes apresentaram pré-natal de alto risco, constatação atribuída ao fato de o HCFMUSP ser um hospital terciário e referência em casos graves. As principais doenças graves associadas foram: a doença hipertensiva grave, a cardiopatia e as doenças tromboembólicas. Diversos estudos confirmam a maior prevalência de doença hipertensiva em gestações múltiplas do que nas gestações únicas. Sibai ${ }^{(11)}$ relata taxa de pré-eclâmpsia grave, em torno de $6,9 \%$, em gestações múltiplas. Nossa casuística revelou taxa de doença hipertensiva grave em 8,8 \% das 817 gestantes estudadas. Como o HCFMUSP é um hospital terciário para onde são encaminhadas as pacientes de maior risco, é esperado maior prevalência de doenças graves. Dentre as 817 pacientes estudadas, 3,1 \% apresentava cardiopatia. Feitosa (102) relata incidência de cardiopatia materna em $4,2 \%$ das gestantes internadas no Departamento de Obstetrícia da Escola Paulista de Medicina.

Das oito pacientes ( $0,9 \%$ da população estudada) com alto risco de fenômenos tromboembólicos na gestação, observou-se trombofilia em três ( $0,3 \%$ da população estudada), trombose venosa profunda em duas $(0,2 \%$ da população) e três foram anticoaguladas por apresentarem alto risco de tromboembolismo $\left(0,4 \%\right.$ da população). Duhl et al ${ }^{(103)}$, em uma revisão 
sobre o tromboembolismo associado ao ciclo gravídico puerperal, relata que sua incidência varia de $0,05 \%$ a $1,8 \%$. Diversos autores referem que a gestação gemelar aumenta o risco de fenômenos tromboembólicos ${ }^{(33,34)}$.

\section{3 - Resultados Maternos}

Tempo de internação puerperal

Este estudo revelou que as pacientes submetidas à cesárea urgente ficaram mais tempo internadas do que aquelas sujeitas ao parto vaginal ou cesárea eletiva. Pallasmaa et al ${ }^{(54)}$ observa que o tempo de internação materna, após uma cesariana eletiva, foi de 4,2 dias; após uma cesariana urgente, foi de 4,9 dias e, após uma cesariana de emergência, foi de 5,1

dias. Luke et al ${ }^{(93)}$ observam que a cesárea esteve relacionada a um maior período de internação materna em gestações gemelares. Rabinovici et al ${ }^{(56)}$ também constatam maior tempo de internação nas pacientes submetidas a uma cesariana.Tendo em vista que nossa casuística revelou que a taxa de complicação foi maior no parto cesária urgente, é esperado que estas pacientes apresentem um maior período de internação.

Taxa de complicação materna puerperal

A incidência de complicações puerperais entre as diferentes vias de parto foi significativamente maior após uma cesariana urgente do que na eletiva.

Os resultados desta pesquisa são compatíveis com os observados por Pallasmaa et al ${ }^{(54)}$, que observam que a taxa de complicação puerperal severa (hemorragia $>1500 \mathrm{ml}$ ou necessidade de transfusão de sangue, histerectomia, reoperação, sepsis, trombose venosa profunda, edema 
pulmonar ou pneumonia) é maior em pacientes submetidas a uma cesária de emergência do que nas submetidas a uma cesariana urgente. Assim, as taxas de complicação de seu estudo são: $7,1 \%$, na cesárea eletiva, $11,7 \%$, na cesárea urgente, e 25,0\% na cesárea de emergência. Os fatores de risco determinantes para a presença de complicações puerperais são a cesariana de emergência, a cesariana urgente, a pré-eclâmpsia, a obesidade materna e o aumento da idade materna.

A taxa de complicação deste estudo é inferior ao relatado por Pallasmaa et al ${ }^{(54)}$, porém é semelhante à observada por Schmitz et al ${ }^{(91)}$, que observam taxa de $4,9 \%$ após um parto vaginal planejado e de $7,0 \%$ na cesariana programada. Esses autores realizam um estudo retrospectivo com 758 gestantes portadoras de uma gestação gemelar. É definido, nesse estudo, como morbidade materna a hemorragia pós-parto severa (que implica transfusão sanguínea, embolização, ligadura arterial ou histerectomia), a transferência para UTI, complicações cardiopulmonares e morte. Geralmente, estudos retrospectivos apresentam menores taxas de complicação materna que estudos prospectivos. Provavelmente, isso é devido ao fato de que alguns dados sejam sub-relatados em estudos retrospectivos. Outro fator, que pode estar relacionado às diferentes taxas de complicação materna, observados na literatura médica, é a variação na definição de morbidade materna grave nos diferentes estudos.

Outros autores, como Simões et al e Liu et al, não observam diferença na incidência de morbidade puerperal materna, após as diferentes vias de parto, em gestações gemelares. Entretanto, seus estudos possuem casuística menor que desta pesquisa (Simões estuda 379 pacientes e Liu, 197) ${ }^{(94,95)}$.

É importante observar que devido à baixa taxa de partos vaginais, o presente estudo sofre perda no poder de demonstrar diferenças nas taxas de complicações entre os partos vaginal e cesárea. 
Taxa de complicações maternas estratificadas

Foi observado neste estudo que as pacientes submetidas à cesariana urgente apresentaram maior incidência de complicações infecciosas que aquelas submetidas à cesárea eletiva. Pallasmaa et al ${ }^{(54)}$ também constatam que a incidência de complicações infecciosas é mais comum nas pacientes submetidas a cesariana urgente do que nas sujeitas à cesariana eletiva. Schneid-Kofman et al ${ }^{(35)}$, num estudo com 19.416 pacientes para determinar fatores de risco associados a infecção de ferida cirúrgica, em pacientes submetidas a cesariana, observam que a cesárea urgente e a gestação gemelar implicam em aumento desta complicação. Alexander et al (57), em um estudo que avalia a influência da manipulação uterina, nas diferentes vias de parto, na determinação de infecção pós-parto, observa maior incidência de endometrite e infecção da ferida cirúrgica, após uma cesariana, do que no parto vaginal. Rabinovic et al ${ }^{(56)}$, no único trabalho randomizado publicado até o momento para comparar os resultados maternos e neonatais de acordo com a via de parto planejada, notam que a morbidade febril puerperal é mais frequente no grupo de parto cesárea planejada do que no grupo de parto vaginal planejado $(40,7 \%$ versus $11,1 \%$, $p<0,05)$. Entretanto, as pacientes randomizadas já se encontravam em trabalho de parto, com dilatação cervical de até $7 \mathrm{~cm}$. A casuística é pequena, com apenas 60 pacientes, nesse trabalho publicado, em 1987. Nada está relatado sobre a profilaxia infecciosa e a incidência de rotura de membranas nas duas vias de parto planejado.

No entanto, Pallasmaa et al ${ }^{(54)}$ observam que a cesariana de emergência também apresenta maior incidência de hemorragia $e$ complicações intraoperatórias do que a realizada eletivamente. Neste trabalho, não observamos diferença na incidência de hemorragia puerperal, histerectomia, lesão cirúrgica, necessidade de reoperação, complicação clínica, tromboembolismo, UTI e morte. Deve-se levar em conta que a casuística de Pallasmaa et al é maior que a deste estudo e as taxas de complicações observadas também são superiores. 
Influência da gestação de alto risco nos resultados maternos

A análise multivariada revelou que a gestação de alto risco foi o principal preditor do resultado materno puerperal adverso. Assim, estas gestações seriam um risco por si só para o desenvolvimento de complicações, não só na gestação, mas também no período pós-parto. Esse fator isolado foi mais importante do que a via de parto na determinação de complicações puerperais. Lydon-Rochelle et al (79), em um estudo populacional retrospectivo, analisam a relação entre a via de parto e a mortalidade materna. Os autores concluem que a cesariana não foi implicada, após a regressão logística, em aumento no risco de morte materna. Ela seria mais um marcador de morbidades graves pré-existentes, que levaria ao aumento no risco de morte, do que um fator de risco isolado. Assim estes autores também observam que comorbidades maternas graves podem ser mais importantes na predição dos resultados maternos que a via de parto.

A análise entre os grupos de alto e baixo risco revelou que as pacientes com maior risco gestacional apresentaram maior incidência de hemorragia puerperal $(7,7 \%$ versus $1,9 \%, p=0,002)$, de complicação clínica $(3,5 \%$ versus $0,1 \%, p=0,0008)$ e de admissão em UTI $(5,6 \%$ versus $0,1 \%$, $p<0,0001)$. Isso provavelmente reflete a patologia de base materna.

Neste estudo, a incidência total de admissão em UTI, independente da via de parto, foi de $1,1 \%$. Baskett e O'Connell ${ }^{(89)}$ relatam que a taxa de admissão em UTI obstétrica varia de 0,05 a 1,7\%, em países desenvolvidos, e de 0,6 A $8,5 \%$, naqueles em desenvolvimento. Suleiman et al ${ }^{(104)}$, estudando a admissão obstétrica em UTI, observam que 59,4\% das pacientes apresentam complicações relacionadas à gestação ou fatores de risco. A admissão em UTI, nas pacientes de alto risco gestacional, no presente estudo,pode ser explicada pelas comorbidades graves como cardiopatia, sangramento aumentado intraoperatório, complicações infecciosas graves e DHEG grave. Vários autores relatam como fatores de 
risco para a admissão em UTI a hemorragia, a doença hipertensiva, a cardiopatia e a sepsis ${ }^{(89,44)}$.

É importante ressaltar que o fato do serviço da Clínica Obstétrica do HCFMUSP ser referência em gestações de alto risco pode se traduzir como um viés de seleção.

Influência da idade gestacional do parto na incidência de complicações puerperais maternas

A análise multivariada revelou que a idade gestacional de nascimento influenciou os resultados maternos. Assim, gestações cujo parto ocorreram em idade gestacional $<33$ semanas apresentaram maior risco de aumento de morbidade puerperal. Isso provavelmente reflete as dificuldades técnicas envolvidas na realização de uma cesárea, em idades gestacionais precoces, em que o segmento uterino ainda não está completamente formado. Os partos, realizados nessas idades gestacionais precoce, também podem ser fruto de um pré-natal com alto risco obstétrico, em que a gestante e/ou seu produto conceptual apresentariam alguma comorbidade grave, elevando assim o risco de complicações maternas.

Häger et al (105) observam que a idade gestacional precoce de nascimento representa fator de risco independente para o estabelecimento de complicações puerperais após uma cesárea. Este estudo prospectivo norueguês com 2.751 pacientes tem por objetivo estabelecer os fatores de risco determinantes no aumento de morbidades maternas após uma cesariana. Os autores concluem que a dilatação do colo uterino, o parto com idade gestacional abaixo de 30 semanas, aquele realizado sob anestesia geral e a macrossomia fetal foram fatores de risco para o desenvolvimento de complicações puerperais. As principais complicações, nesses partos prematuros, são a necessidade de reoperação e o desenvolvimento de hematoma. 
Nesta casuística, observou-se que os partos com idade gestacional inferior a 33 semanas apresentaram apenas maior risco de infecções não cirúrgicas ( $I G<33$ sem $=2,1 \%$ versus $I G>33$ sem $=0,1 \%, p=0,02$ ). Kankuri et al (42) observam que partos pré-termo aumentam o risco de sepsis periparto, em 2,7 vezes, em comparação com aqueles realizados no termo. Pallasmaa et al ${ }^{(54)}$ notam que o parto realizado abaixo de 37 semanas é considerado fator de risco para a necessidade de reoperações. Isto não foi observado em nossa casuística. Isto pode estar relacionado ao maior número de pacientes envolvidas em seu trabalho.

\section{4 - Evolução temporal da taxa de cesariana e taxa de complicação puerperal}

Este estudo revelou aumento significativo na taxa de cesarianas, em gestação gemelares, no período estudado. Mas a taxa de complicação permaneceu estável no decorrer dos anos. Isso provavelmente reflete o risco intrínseco de complicação de cada via de parto. Foi observado, também, aumento na incidência de cesáreas eletivas, em detrimento dos partos vaginais e de cesáreas urgentes. Isso mostra aumento da intervenção obstétrica, provavelmente, decorrente do fato de a corionicidade passar a ser determinante do momento da resolução das gestações gemelares, a partir de 2002.

Ananth e Joseph ${ }^{(67)}$, estudando o impacto da intervenção obstétrica na mortalidade perinatal, observam que a maior vigilância no pré-natal de pacientes com gestação gemelar leva a um aumento da intervenção obstétrica (induções de parto e cesáreas). Esse fato é acompanhado de um declínio nas taxas de óbito intrauterino e de mortalidade perinatal , embora a taxa de prematuridade tenha aumentado. Isso seria influenciado pelos recentes avanços observados na neonatologia, como o uso de surfactante, corticoide para a maturação pulmonar e a ventilação mecânica. $O$ desenho 
deste estudo não permite estudar a taxa de óbitos intrauterinos. A mortalidade neonatal não foi apreciada nesse primeiro momento.

Atualmente, não há evidência na literatura suficiente para a determinação da melhor via de parto, em gestações gemelares. Na prática clínica esta decisão é baseada em vários fatores como a apresentação fetal, a presença de complicações materno-fetais, os antecedentes pessoais clínicos e obstétricos maternos e a habilidade do obstetra no manejo do parto destas gestações. A determinação da melhor idade gestacional de nascimento destas gestações também é motivo de discussão na literatura.

Os resultados do "Twin Birth Study"(68), um estudo randomizado prospectivo multicêntrico, logo serão conhecidos e deverão ajudar no esclarecimento sobre a melhor via de parto em gestações múltiplas. 


\section{8 - CONCLUSÃO}

- Complicações maternas, após o parto, foram observadas em $7 \%$ das gestações gemelares.

- A freqüência dessas complicações é 2,3 vezes maior após cesárea urgente, quando comparada com a eletiva.

- Outros fatores que se associaram de forma significativa com a ocorrência dessas complicações foram:

- presença de gestação de alto risco: o risco de complicações maternas aumentou em 3,3 vezes.

- a idade gestacional no parto: gestações abaixo de 33 semanas apresentaram risco aumentado em 1,8 vezes. 


\section{$\underline{9-\text { Anexos }}$}

\section{Anexo A}

\section{APROVAÇÃO}

A Comissão de Ética para Análise de Projetos de Pesquisa CAPPesqa da Diretoria Clínica do Hospital das Clínicas e da Faculdade de Medicina da Universidade de São Paulo, em sessão de 19/11/2008, APROVOU ○ Protocolo de Pesquisa n 0849/08, intitulado: "ESTUDO DA INFLUÊNCIA DA VIA DE PARTO NA MORBIMORTALIDADE MATERNA E FETAL NOS PARTOS DE GESTAÇŌES GEMELARES OCORRIDOS NO HOSPITAL DAS CLÍNICAS DA FACULDADE DE MEDICINA DA UNIVERSIDADE DE SĀO PAULO ENTRE 1993 E 2008." apresentado pelo Departamento de OBSTETRÍCIA E GINECOLOGIA.

Cabe ao pesquisador elaborar e apresentar à CAPPesq, os relatórios parciais e final sobre a pesquisa (Resolução do Conselho Nacional de Saúde $n^{\circ} 196$, de 10/10/1996, inciso IX.2, letra "c").

Pesquisador (a) Responsável: Dr. Adolfo Wenjaw Liao Pesquisador (a) Executante: Dra. Sonia Stach

CAPPesq, 21 de Novembro de 2008

Prof. Dr. Eduardo Massad Presidente da Comissão de Ética para Análise de Projetos de Pesquisa

\footnotetext{
Comissão de Ética para Análise de Projetos de Pesquisa do HCFMUSP e da FMUSP Diretoria Clinica do Hospital das Clinicas da Faculdade de Medicina da Universidade de São Paulo Rua Ovidio Pires de Campos, 225, 5ªndar - CEP 05403010 - Såo Paulo - SP Fone: 01130696442 Fax. 01130696492 e-mail: cappesq@hcnet.usp.br / secretariacappesq2@hcnet.usp.br
} 


\section{Anexo B}

\section{Clínica Obstétrica - HCFMUSP / Setor de Medicina Fetal Projeto Pesquisa - Parto em Gestaçāo Gemelar}

Dra. Sônia Christina Leme Stach

Instrumento de Coleta de Dados

Identificação:

Nome: RG- HC:

Idade: Cor: B MA P $G$ $P$ A:

Antecedentes Pessoais:

Hábito Materno: Fumo (

Uso de substâncias llicitas ( )

Dados do Parto:

Idade Gestacional do Parto:

Data do Parto:

Indicação da Internaçăo:

Indicaçăo da Resolução da Gestação:

Indicaçăo da Via de Parto:

Tipo de Parto:

Realização de Corticóide: Sim ( )

Näo ( )

Corionicidade da Placenta:

Apresentaçăo dos fetos:

Intervalo de nascimento:

Tempo de Internaçāo Materna: 
Dados do RN:

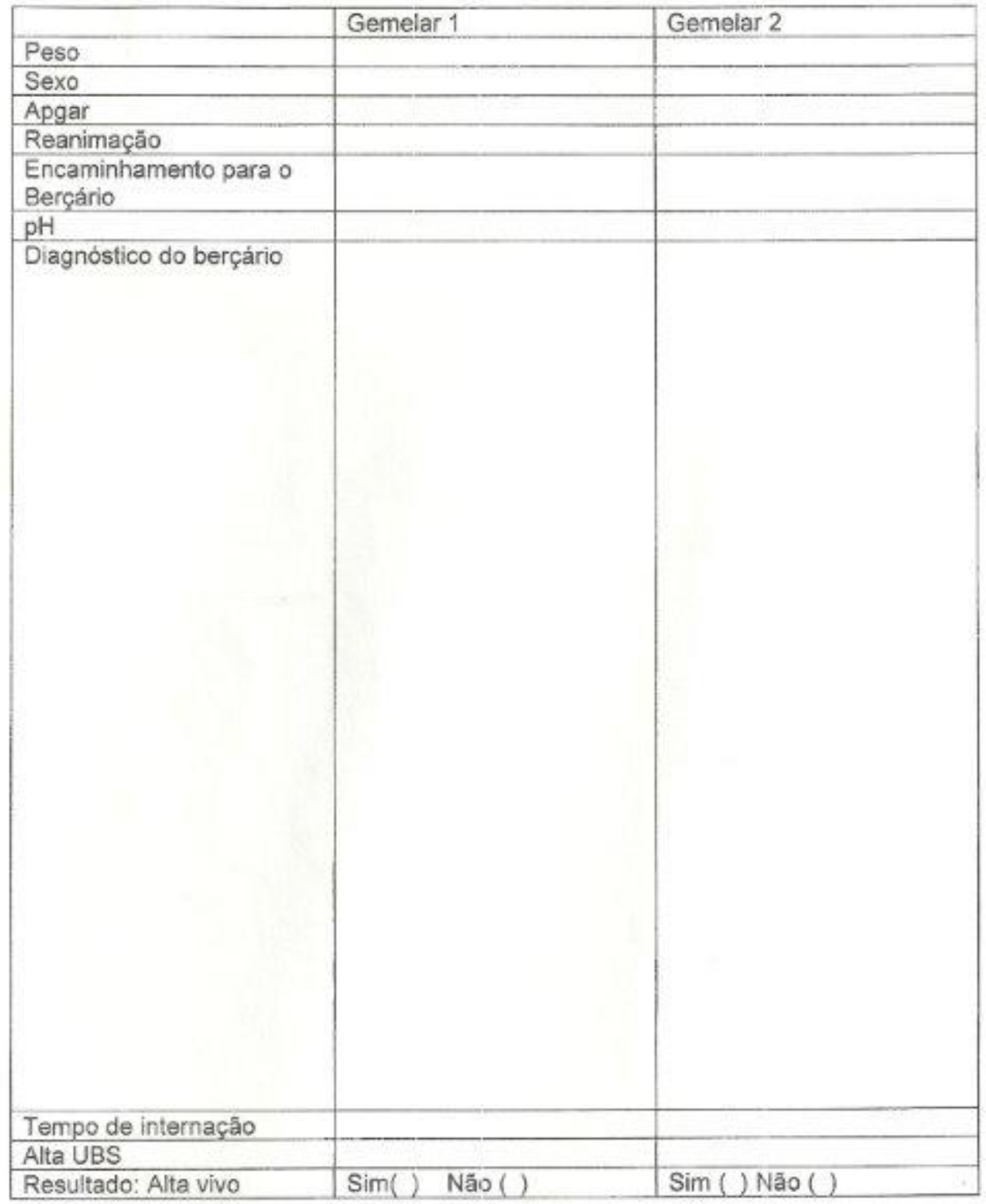




\section{Complicaçōes}

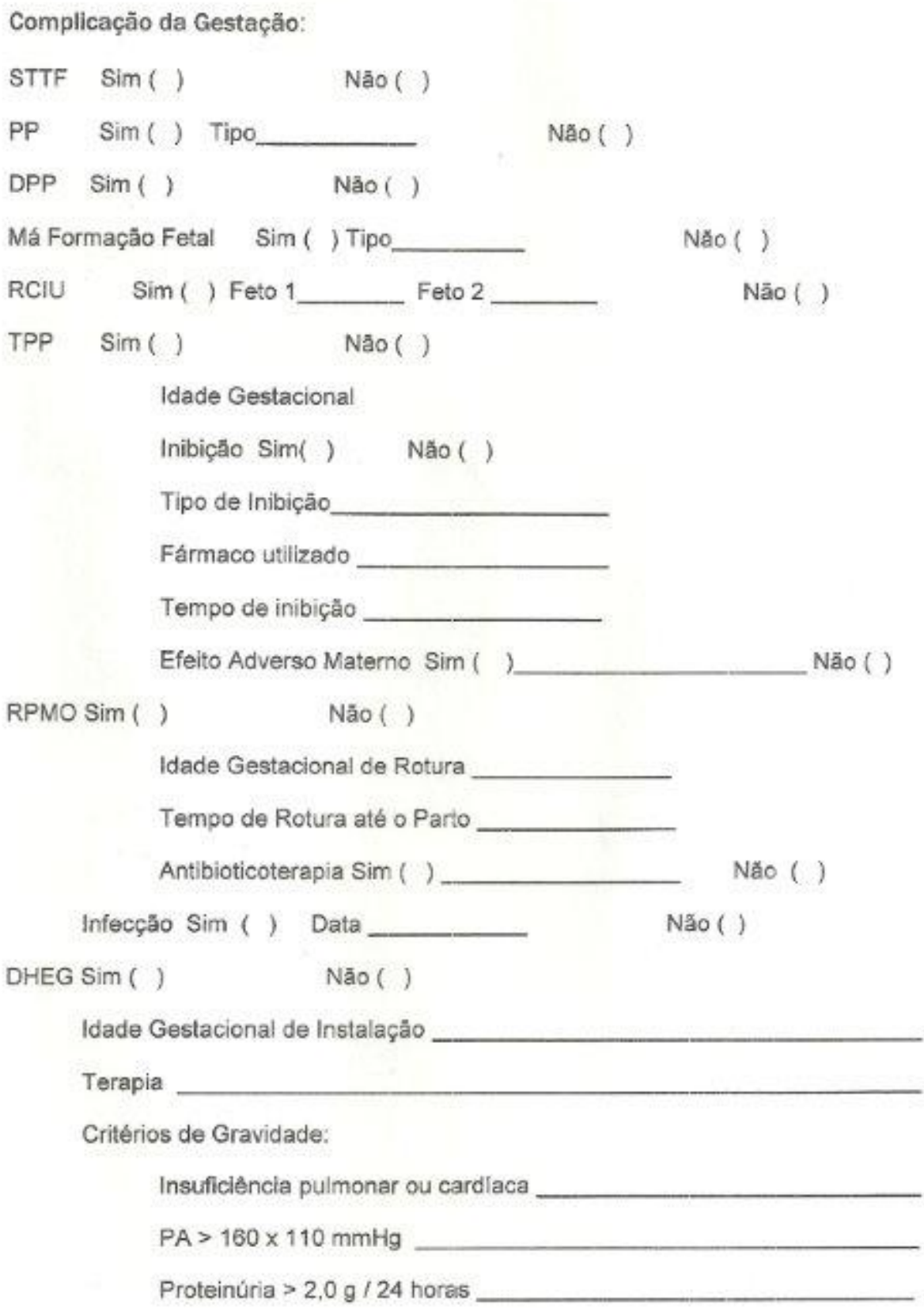


Alteração na função renal

Imine̊ncia de Eclâmpsia

HELLP Sindrome

OUTROS :

Complicação Materna

Morte $\operatorname{Sim}($ ) Năo( )

UTI $\operatorname{Sim}($ ) Năo( )

Hemorragia Pós parto com necessidade de transfusăo de sangue Sim ( ) Năo ( )

Quantidade de sangue transfundido

$\begin{array}{lll}\text { Infecçâo } & \text { Sim ( ) Năo ( ) } \\ & \text { Local de Infecção_ } \\ & \text { Tratamento }\end{array}$

Tratamento

$\begin{array}{lc}\text { Tocotraumatismo } \operatorname{Sim}(\text { ) } & \text { Não( ) } \\ \text { Deiscância de cicatriz } \operatorname{Sim}(\text { ) } & \text { Năo( ) } \\ \text { Tromboembolismo } \operatorname{Sim}(\text { ) } & \text { Năo( ) }\end{array}$

Outros :

Complicação Fetal

Distúrbio respiratório Sim ( )

Năo( )

Morbidade Neonatal Grave $\operatorname{Sim}($ )

Nằ ( )

Trauma de Parto 
Apgar de $5^{\circ}$. Minuto $<4$

$\mathrm{pH}$ arterial $<7,0$

Hemorragia Intracraniana

Transferencia para UTI

Necessidade de Ventilaçăo Mecånica

Infeç̧ăo Neonatal

Morte

Outros: 


\section{0 - Referência bibliográfica}

1-Blickstein I. Definition of multiple pregnancy, in Blickstein I and Keith L. Multiple pregnancy: epidemiology, gestation \& perinatal outcome, United Kingdom: Informa Healthcare, editor; 2006, Second edition. p 85-6.

2-Smulian JC, Ananth CV, Kinzler WL, Kontopoulos E, Vintzileos AM. Twin deliveries in the United States over three decades : an age-period-cohort analysis. Obstet Gynecol. 2004; 104 (2): 278-85.

3-Kogan MD, Alexander GR, Kotelchuck M, MacDorman MF, Buekens P, Martin JA, et al. Trends in twin birth outcomes and prenatal care utilization in the United States, 1981-1997 . JAMA. 2000; 284 (3): 335-40.

4-Martin JA, Park MM. Trends in twin and triplet births: 1980-97, Natl Vital Stat Rep. 1999; 47 (24): 1-16.

5- Ministério da Saúde. Sistema de Informações de Nascidos Vivos (SINASC). Atualização ano 2011. Brasília 2011. Disponível em http://tabnet.datasus.gov.br/cgi/deftohtm.exe?sinasc/cnv/nvuf.def

6-Bortolus R, Parazzini F, Chatenoud L, Benzi G, Bianchi MM, Marini A. The epidemiology of multiple births. Hum Reprod Update. 1999; 5 (2): 179-87.

7-Hoekstra C, Zhao ZZ, Lambalk CB, Willemsen G, Martin NG, Boomsma DI, et al. Dizygotic twinning . Hum Reprod Update. 2008; 14 (1): 37-47.

8-Bittar RE, Pereira PP, Liao AW. Gestação múltipla. In: Zugaib M. Obstetrícia. São Paulo: Manole; 2008: 679-98. 
9-Blondel B, Macfarlane A, Gissler M, Breart G, Zeitlin J, Macfarlane A, et al. Preterm birth and multiple pregnancy in European countries participating in the PERISTAT project. BJOG. 2006; 113 (5): 528-35.

10- Alexander GR, Salihu HM. Perinatal outcomes of singleton and multiple births in the United States, 1995-98. In: Blickstein I and Keith L. Multiple pregnancy: epidemiology, gestation \& perinatal outcome, United Kingdom: Informa Healthcare, editor; 2006, Second edition p 3-10.

11- Sibai BM, Hauth J, Caritis S, Lindheimer MD, MacPherson C, Klebanoff $M$, et al. Hypertensive disorders in twin versus singleton gestations. Am J Obstet Gynecol. 2000; 182 (4): 938-42.

12-Buhling K, Henrich W, Starr E, Lubke M, Bertram S, Siebert G, et al. Risk for gestational diabetes and hypertension for women with pregnancy compared to singleton pregnancy. Arch Gynecol Obstet. 2003; 269 (1): 33-6.

13- Blickstein I, Maternal Mortality, in Blickstein I and Keith L, Multiple pregnancy: epidemiology, gestation \& perinatal outcome. United Kingdom: Informa Healthcare, editor; 2006, Second edition p 492-9.

14- Kiely JL. The epidemiology of perinatal mortality in multiple births. Bull N. Y. Acad. Med. 1990; 66 (6): 618-37.

15-Ananth CV, Smulian JC, Demissie K, Vintizleos AM, Knuppel RA. Placental abruption among singleton and twin births in the United States: risk factor profiles. Am J Epidemiol. 2001; 153 (8): 771-8.

16-Ananth CV, Demissie K, Smulian JC, Vintzileos A. M. Placenta previa in singleton and twin births in the United States, 1989 through 1998 : a comparison of risk factor profiles and associated conditions. Am J Obstet Gynecol. 2003; 188 (1): 275-81. 
17- Mathews TJ, MacDorman MF. Infant Mortality Statistics from the 2004 Period Linked Birth/Infant Death Data Set. Natl Vital Stat Rep. 2007; 55 (14): $1-32$.

18- Wen SW, Fung KFK, Oppenheimer L, Demissie K, Yang Q, Walker M. Neonatal morbidity in second twin according to gestational age at birth and mode of delivery . Am J Obstet Gynecol. 2004; 191 (3): 773-7.

19- Wen SW, Fung KFK, Oppenheimer L, Demissie K, Yang Q, Walker M. Neonatal mortality in second twin according to cause of death, gestational death , and mode of delivery . Am J Obstet Gynecol. 2004; 191 (3): 778-83.

20- Kontopoulos EV, Ananth CV, Smulian JC, Vintzileos AM. The impact of route of delivery and presentation on twin neonatal and infant mortality : a population-based study in the USA, 1995-97. J Matern Fetal Neonatal Med. 2004; 15 (4): 219-24.

21- Ginsberg NA, Levine EM. Delivery of the second twin. Int J Gynaecol Obstet. 2005; 91 (3): 217-20.

22- American College of Obstetricians and Gynecologists Committee on Practice Bulletins-Obstetrics. ACOG Practice Bulletin \#56: Multiple gestation: complicated twin, triplet, and high-order multifetal pregnancy. Obstet Gynecol 2004; 104(4): 869-83.

23- Barrett J, Bocking A. The SOGC Consensus Statement: Management of twin pregnancies Part 1. J Soc Obstet Gynecol Can. 2000; 91: 5-15.

24- Yang Q, Wen SW, Chen Y, Krewski D, Fung Kee Fung K, Walker M. Neonatal death and morbidity in vertex-nonvertex second twins according to 
mode of delivery and birth weight. Am J Obstet Gynecol. 2005; 192 (3): 8407.

25- Smith GCS, Fleming KM, White IR. Birth order of twins and risk of perinatal death related to delivery in England, Northern Ireland, and Wales, 1994-2003: retrospective cohort study. BMJ. 2007; 334 (7593): 576-8.

26-Smith GC, Shah I, White IR, Pell JP, Dobbie R. Mode of delivery and the risk of delivery-related perinatal death among twins at term: a retrospective cohort study of 8073 births. BJOG. 2005;112 (8): 1139-44.

27- Armson BA, O'Connell C, Persad V, Joseph KS, Young DC, Baskett TF. Determinants of Perinatal Mortality and Serious Neonatal Morbidity in the Second Twin. Obstet Gynecol. 2006 ; 108 (3, Part 1): 556-64.

28- Hogle KL, Hutton EK, McBrien KA, Barret JFR, Hannah ME. Cesarean delivery for twins : a systematic review and meta-analysis. Am J Obstet Gynecol. 2003; 188 (1): 220-7.

29- Bateman BT, Berrman MF, Riley LE, Leffert LR. The epidemiology of postpartum hemorrhage in a large nationwide sample of deliveries. Anesth Analg. 2010; 110 (5): 1368-73.

30- Rossem J, Okland I, Nilsen OB, Eggebø TM. Is there an increase of postpartum hemorrhage, and is severe hemorrhage associated with more frequent use of obstetric interventions?. Acta Obstet Gynecol Scand. 2010; 89 (10): 1248-55.

31- Blickstein I. Maternal mortality in twin gestations. J Reprod Med. 1997; 42 (11): 680-4. 
32- Suonio $S$, Huttunen M. Puerperal endometritis after abdominal twin delivery. Acta Obstet Gynecol Scand. 1994; 73 (4): 313-5.

33- Jacobsen AF, Skjeldestad FE, Sandset PM. Incidence and risk patterns of venous thromboembolism in pregnancy and puerperium- a register-based case-control study. Am J Obstet Gynecol. 2008; 198(2): 233. e1-7.

34- Simpson EL, Lawrenson RA, Nightingale AL, Farmer RD. Venous thromboembolism in pregnancy and the puerperium: incidence and additional risk factors from a London perinatal database. BJOG. 2001; 108 (1): 56-60.

35-Schneid-Kofman N, Sheiner E, Levy A, Holcberg G. Risk factors for wound infection following cesarean deliveries. Int J Gynaecol Obstet. 2005; 90 (1): 10-5.

36- Lee HC, Gould JB, Boscardin WJ, El-Sayed YY, Blumenfeld YJ. Trends in cesarean delivery for twin births in the United States: 1995-2008. Obstet Gynecol. 2011; 118 (5): 1095-101.

37- Liu S, Liston RM, Joseph KS, Heaman M, Sauve R, Kramer MS. Maternal mortality and severe morbidity associated with low-risk planned cesarean delivery versus planned vaginal delivery at term. CMAJ. 2007; 176 (4): 455-60.

38- Kamilya G, Seal SL, Mukherji J, Bhattacharyya S K, Hazra A. Maternal mortality and cesarean delivery: an analytical observational study. J Obstet Gynaecol Res. 2010; 36 (2): 248-53.

39- Deneux-Tharaux C, Carmona E, Bouvier-Colle MH, Bréart G. Postpartum maternal mortality and cesarean delivery. Obstet Gynecol. 2006; 108 (3 pt 1): $541-48$ 
40- Simoes E, Kunz S, Bosing-Schwenkglenks M, Schmahl FW. Association between method of delivery and puerperal infectious complications in the perinatal database of Baden-Württemberg 1998-2001. Gynecol Obstet Invest. 2005; 60 (4): 213-7.

41- Leth RA, Møller JK, Thomsen RW, Uldbjerg N, Nørgaard M. Risk of selected postpartum infections after cesarean section compared with vaginal birth: a five-year cohort study of 32.468 women. Acta Obstet Gynecol Scand. 2009; 88 (9):976-83.

42- Kankuri E, Kurki T, Carlson P, Hiilesmaa V. Incidence, treatment and outcome of peripartum sepsis. Acta Obstet Gynecol Scand. 2003; 82 (8): 730-5.

43-- Acosta CD, Bhattacharya S, Tuffnell D, Kurinczuk JJ, Knight M. Maternal sepsis : a scottish population-based case-control study . BJOG. 2012; 119 (4): 474-83.

44- Panchal S, Arria AM, Harris AP. Intensive Care utilization during hospital admission for delivery: prevalence, risk factors, and outcomes in a statewide population. Anesthesiology. 2000; 92 (6): 1537-44.

45- Liu S, Heaman M, Joseph KS, Liston RM, Huang L, Sauve R, et al. Risk of maternal postpartum readmission associated with mode of delivery. Obstet Gynecol. 2005; 105 (4): 836-42.

46- Declerq E, Barger M, Cabral HJ, Evans SR, Kotelchuck M, Simon C, et al. Maternal outcomes associated with planned primary cesarean births compared with planned vaginal births. Obstet Gynecol. 2007; 109(3):669-77. 
47-Kacmar J, Bhimani L, Boyd M, Shah-Hosseini R, Peipert J. Route of delivery as a risk factor for emergent peripartum hysterectomy: a casecontrol study. Obstet Gynecol. 2003; 102 (1): 141-5.

48-Selo-Ojeme DO, Bhattacharjee P, Izuwa-Njoku NF, Kadir RA. Emergency peripartum hysterectomy in a tertiary London hospital. Arch Gynecol Obstet. 2005; 271 (2): 154-9.

49-Simoes E, Kunz S, Bosing-Schwenkglenks M, Schmahl FW. Association between method of delivery, puerperal complication rate and postpartum hysterectomy. Arch Gynecol Obstet. 2005; 272 (1): 43-7.

50-Demirci O, Tuğrul AS, Yilmaz E, Tosun Ö, Demirci E, Eren YS. Emergency peripartum hysterectomy in a tertiary obstetric center: nine years evaluation. J Obstet Gynaecol Res. 2011; 37 (8): 1054-60.

51-Awan N, Bennett MJ, Walters WA. Emergency peripartum hysterectomy: a 10-year review at the Royal Hospital for Women, Sydney. Aust N Z J Obstet Gynaecol. 2011; 51 (3): 210-5.

52-Skjeldestad FE, Oian P. Blood loss after cesarean delivery: a registrybased study in Norway, 1999-2008. Am J Obstet Gynecol. 2012; 206 (1): 76.e1-7.

53-Burrows LJ, Meyn LA, Weber AM. Maternal morbidity associated with vaginal versus cesarean delivery. Obstet Gynecol. 2004; 103 (5 Pt 1): 90712.

54-Pallasmaa N, Ekblad U, Aitokallio-Tallberg A, Uotila J, Raudaskoski T, Ulander VM, et al. Cesarean delivery in Finland: maternal complications and obstetric risk factors. Acta Obstet Gynecol Scand. 2010; 89 (7): 896-902. 
55-Sentilhes L, Goffinet F, Talbot A, Diguet A, Verspyck E, Cabrol D, et al. Attempted vaginal versus planned cesarean delivery in 195 breech first twin pregnancies . Acta Obstet Gynecol Scand. 2007; 86 (1): 55-60.

56-Rabinovici J, Barkai G, Reichman B, Serr DM, Mashiach S. Randomized management of the second nonvertex twin: vaginal delivery or cesarean section. Am J Obstet gynecol. 1987; 156 (1): 52-6.

57- Alexander JM, Gilstrap LC, Cox SM, Ramin SM. The relationship of infection to method of delivery in twin pregnancy. Am J Obstet gynecol. 1997; 177 (5): 1063-6.

58-Knight M, Kurinczuk JJ, Spark P, Brocklehurst P. Cesarean delivery and peripartum hysterectomy. Obstet Gynecol. 2008; 111 (1): 97-105.

59-Haest KM, Roumen FJ, Nijhuis JG. Neonatal and maternal outcomes in twin gestations >ou=32 weeks according to the planned mode of delivery. Eur J Obstet Gynecol Reprod Biol. 2005; 123 (1): 17-21.

60-Simões T, Aboim L, Costa A, Ambrosio A, Alves S, Blickstein I. Puerperal complications following elective cesarean sections for twin pregnancies. J Perinat Med. 2007; 35 (2): 104-7.

61- Martin JA., Hamilton BE., Ventura SJ., Osterman MJ, Kirmeyer S, Mathews TJ, et al. Births: final data for 2009. Natl Vital Stat Rep. 2011; 60 (1): $1-70$.

62- NIH State-of-the-Science Conference Statement on cesarean delivery on maternal request. 1 NIH Consens State Sci Statements. 2006; 23 (1):1-29. 
63-Villar J, Valladares E, Wojdyla D, Zavaleta N, Carroli G, Velazco A, et al. Caesarean delivery rates and pregnancy outcomes: the 2005 WHO global survey on maternal and perinatal health in Latin America. Lancet. 2006; 367 (9525): 1819-29.

64- Francisco RPV, Fonseca ESVB, Sapienza AD. Cesárea. In: Zugaib M. Obstetrícia. São Paulo: Manole; 2008: 407-28.

65-Hannah ME, Hannah WJ, Hewson SA, Hodnett ED, Saigal S, Willan AR. Planned caesarean section versus planned vaginal birth for breech presentation at term: a randomised multicentre trial. Lancet. 2000; 356 (9239): 1375-83.

66- Kogan MD, Alexander GR, Kotelchuck M, MacDorman MF, Buekens P, Martin JA, Papiernik E. Trends in twin birth outcomes and prenatal care utilization in the United States, 1981-1997. JAMA. 2000; 284 (3): 335-41.

67- Ananth CV, Joseph KS. Impact of obstetric intervention on trends in perinatal mortality. In: Blickstein I and Keith L. Multiple pregnancy: epidemiology, gestation \& perinatal outcome, United Kingdom: Informa Healthcare, editor; 2006, Second edition, p 651-9.

68- Barrett J.The Twin birth study: planned caesarean section versus planned vaginal birth for twins at 32-38 weeks gestation (trial online).ISRCTN register. Disponível em http://www.controlled-trials.com/ISRCTN74420086

69- Kalish RB, Chervenak FA. The optimum route of delivery, In: Blickstein I and Keith L. Multiple pregnancy: epidemiology, gestation \& perinatal outcome, United Kingdom: Informa Healthcare, editor; 2006, Second edition, p 660-7. 
70- Hofmeyr GJ, Drakeley AJ. Delivery of twins. Baillieres Clin Obstet Gynaecol. 1998; $12(1)$ : 91-108.

71- Barrett JF, Ritchie WK, Twin delivery . Best Pract Res Clin Obstet Gynaecol. 2002; 16 (1): 43-56.

72- Blickstein I. Cesarean section for all twins? J Perinat Med. 2000; 28 (3): 169-74.

73- American College of Obstetricians and Gynecologists. Special Problems of multiple gestation. ACOG educational bulletin. Int J Gynaecol Obstet. 1999; 64 (3): 323-33.

74-Peaceman AM, Kuo L, Feinglass J. Infant morbidity and mortality associated with vaginal delivery in twin gestations. Am J Obstet Gynecol. 2009; 200 (4): 462.e1-6.

75- Yang Q, Wen SW,Chen Y, Krewski D, Fung FK, Walker M. Neonatal mortality and morbidity in vertex-vertex second twins according to mode of delivery and birth weight. J Perinat. 2006; 26: 3-10.

76- Allen VM, O'Connell CM, Liston R, Baskett TF. Maternal Morbidity Associated With Cesarean Delivery Without Labor Compared With Spontaneous Onset of Labor at Term. Obstet Gynecol. 2003; 102(3): 477-82.

77- Wax JR. Maternal request cesarean versus planned spontaneous vaginal delivery: maternal morbidity and short term outcomes. Semin Perinatol. 2006; $30(5): 247-52$.

78- Nomura RMY, Alves EA , Zugaib M. Complicações maternas associadas ao tipo de parto em hospital universitário. Rev Saúde Pública. 2004; 38 (1): 9-15. 
79-Lydon-Rochelle M, Holt VL, Easterling TR, Martin DP. Cesarean delivery and postpartum mortality among primiparas in Washington State, 19871996(1). Obstet Gynecol. 2001; 97 (2): 169-74.

80-Yang Q, Wen SW, Oppenheimer L, Chen XK, Black D, Gao J, et al. Association of caesarean delivery for first birth with placenta praevia and placental abruption in second pregnancy. BJOG. 2007 ; 114 (5): 609-13.

81-Lindqvist $P$, Dahlbäck $B$, Marŝál K. Thrombotic risk during pregnancy: a population study. Obstet Gynecol. 1999 ; 94 (4): 595-9.

82-Samuelsson E, Hellgren M, Högberg U. Pregnancy-related deaths due to pulmonary embolism in Sweden. Acta Obstet Gynecol Scand. 2007; 86 (4): 435-43.

83-Sharma S, Monga D. Venous thromboembolism during pregnancy and the post-partum period: incidence and risk factors in a large Victorian health service. Aust N Z J Obstet Gynaecol. 2008; 48 (1): 44-9.

84- Lanska DJ, Kryscio RJ. Risk Factors for Peripartum and Postpartum Stroke and Intracranial Venous Thrombosis. Stroke 2000; 31: 1274-82.

85- Conde-Agudelo A, Belizán JM, Lindmark G. Maternal Morbidity and Mortality Associated With Multiple Gestations. Obstet Gynecol. 2000; 95 (6 pt 1): 899-904.

86-Suzuki S, Inde $\mathrm{Y}$, Igarashi M, Miyake $\mathrm{H}$. Elective cesarean as a risk factor for transfusion after delivery of twins. J Nippon Med Sch. 2008; 75 (4): 247-9.

87-Combs CA, Murphy EL, Laros RKJr. Factors associated with postpartum hemorrhage with vaginal birth. Obstet Gynecol. 1991; 77 (1): 69-76. 
88-Bodelon C, Bernabe-Ortiz A, Schiff MA, Reed SD. Factors associated with peripartum hysterectomy. Obstet Gynecol. 2009; 114 (1):115-23.

89-Baskett TF, O'Connell CM. Maternal critical care in obstetrics. J Obstet Gynaecol Can. 2009; 31 (3): 218-21.

90-Senat MV, Ancel PY, Bouvier-Colle MH, Bréart G. How does multiple pregnancy affect maternal mortality and morbidity? Clin Obstet Gynecol. 1998; 41 (1): 78-83.

91-Schmitz T, Carnavalet CC, Azria E, Lopez E, Cabrol D, Goffinet F. Neonatal outcomes of twin pregnancy according to the planned mode of delivery. Obstet Gynecol. 2008; 111 (3): 695-703.

92-Mauldin JG, Newman RB, Mauldin PD. Cost-effective delivery management of the vertex and nonvertex twin gestation. Am J Obstet Gynecol. 1998; 179 (4): 864-9.

93-Luke B, Brown MB, Alexandre PK, Kinoshi T, O'Sullivan MJ, Martin D, et al. The cost of twin pregnancy: maternal and neonatal factors. Am J Obstet Gynecol. 2005; 192 (3): 909-15.

94-Simões T, Aboim L, Costa A, Ambrosio A, Alves S, Blickstein I. Puerperal complications following elective Cesarean sections for twin pregnancies. J Perinat Med. 2007; 35 (2): 104-7.

95-Liu AL, Yung WK, Yeung HN, Lai SF, Lam MT, Lai FK, et al. Factors influencing the mode of delivery and associated pregnancy outcomes for twins: a retrospective cohort study in a public hospital. Hong Kong Med J. 2012; 18 (2): 99-107. 
96- Minakami H, Sato I. Reestimanting date of delivery in multifetal pregnancies. JAMA. 1996; 275 (18): 1432-34.

97- Hartley RS, Emanuel I, Hitti J. Perinatal mortality and neonatal morbidity rates among twin pairs at different gestational ages: optimal delivery timing at 37 to 38 weeks' gestation. Am J Obstet Gynecol, 2001; 184 (3): 451-8.

98- Lee YM, Wylie BJ, Simpson LL, D'Alton ME. Twin chorionicity and the risk of stillbirth . Obstet Gynecol, 2008: 111 (2 Pt 1): 301-8.

99- Simões T, Amaral N, Lerman R, Ribeiro F, Dias E, Blickstein I. Prospective risk of intrauterine death of monochorionic-diamniotic twins. Am J Obstet Gynecol. 2006; 195 (1): 134-9.

100- Smith NA, Wilkins-Haug L, Santolaya-Forgas J, Acker D, Economy KE, Benson CB, et al. Contemporary management of monochorionic diamniotic twins: outcomes and delivery recommendations revisited. Am J Obstet Gynecol. 2010; 203 (2): 133.e1-6.

101- Assunção RA, Liao AW, Brizot ML, Krebs VL, Zugaib M. Perinatal outcome of twin pregnancies delivered in a teaching hospital. Rev Assoc Med Bras 2010; 56 (4): 447-51.

102- Feitosa HN., Moron AF, Born D, Almeida PAM. Mortalidade maternal por cardiopatia. Rev Saúde Públ. 1991; 25 (6): 443-51.

103- Duhl AJ, Paidas MJ, Ural SH, Branch W, Casele H, Cox-Gill J, et al. Antithrombotic therapy and pregnancy: consensus report and recommendations for prevention and treatment of venous thromboembolism and adverse pregnancy outcomes. Am J Obstet Gynecol. 2007; 197 (5): 457.e1-21. 
104- Al-Suleiman SA, Qutub HO, Rahman J,Rahman MS. Obstetric admissions to the intensive care unit: a 12-year review. Arch Gynecol Obstet. 2006; 274 (1): 4-8.

105-Häger RM, Daltveit AK, Hofoss D, Nilsen ST, Kolaas T, Øian P, Henriksen T. Complications of cesarean deliveries: rates and risk factors. Am J Obstet Gynecol. 2004; 190 (2): 428-34. 